\title{
Processing methodology for the ITS_LIVE Sentinel-1 ice velocity product
}

\author{
Yang Lei ${ }^{1}$, Alex S. Gardner ${ }^{2}$, Piyush Agram ${ }^{1}$ \\ ${ }^{1}$ Division of Geological and Planetary Science, California Institute of Technology, Pasadena, 91125, USA \\ $5 \quad{ }^{2}$ Jet Propulsion Laboratory, California Institute of Technology, Pasadena, 91109, USA
}

Correspondence to: Yang Lei (ylei@caltech.edu)

\begin{abstract}
The NASA MEaSUREs Inter-mission Time Series of Land Ice Velocity and Elevation (ITS_LIVE) project seeks to accelerate understanding of critical glaciers and ice sheet processes by providing researchers with global, low-latency, comprehensive and state-of-the-art records of surface velocities and elevations as observed from space. Here we describe the

10 image-pair ice velocity product and processing methodology for ESA Sentinel-1 radar data. We demonstrate improvements to the core processing algorithm for dense offset tracking, "autoRIFT", that provides finer resolution and higher accuracy data products with improved computational efficiency when compared to earlier versions. A novel calibration is applied to the data to correct for Sentinel-1A/B subswath- and full swath-dependent geolocation errors caused by systematic issues with the instruments. Sentinel-1's C-band images are affected by variations in the total electron content of the ionosphere that

15 results in large velocity errors in the azimuth (along-track) direction. To reduce these effects slant-range (line-of-sight or LOS) velocities are used and accompanied by LOS parameters that support map coordinate (x/y) velocity inversion from ascending and descending slant-range offset measurements, as derived from 2 image-pairs. The described product and methods comprise the MEaSUREs ITS_LIVE Sentinel-1 Image-Pair Glacier and Ice Sheet Surface Velocities: Version 2 (https://its-live.jpl.nasa.gov).
\end{abstract}

\section{Introduction}

As the planet warms in response to increased concentrations of greenhouse gases in the atmosphere, glaciers and ice sheet are losing more mass to the world's oceans, leading to accelerated rates of sea level rise (IPCC AR6). Glaciers and ice sheets are losing mass through both accelerated melting and solid ice discharge into the ocean via enhanced flow. How glacier and ice sheet flow will change in the future is one of the largest uncertainties in projections of sea level change. Tracking of

25 features in repeat satellite imagery provides a vantage point for measuring ice motion over continental scales (Bindschadler and Scambos, 1991; Frolich and Doake, 1998), providing insights into the processes that drive large-scale changes in flow. Surface velocities have been successfully derived from both optical and radar imagery including NASA's Landsat 4/5/6/7/8 (Fahnestock et al., 2016; Gardner et al., 2018), ESA’s Sentinel-1 (Nagler et al., 2015; Andersen et al., 2020; Solgaard et al., 2021) and Sentinel-2 (Kääb et al., 2016; Nagy and Andreassen, 2019), DLR's TerraSAR-X and TanDEM-X (Joughin et al.,

30 2010) and through multi-mission synthesis (Miles et al., 2017; Mouginot et al., 2017; Derkacheva et al., 2020).

Surface velocities can be derived from pairs of radar images using multiple techniques. The most accurate technique (i.e. $\mathrm{cm}$ level for Sentinel-1) is Synthetic Aperture Radar Interferometry (InSAR) that is highly sensitive to measured changes in range from repeat-pass observations (Joughin et al., 1995; Rignot et al., 1995; Gray et al., 1998; Joughin et al., 1998; Joughin 
https://doi.org/10.5194/essd-2021-393

Preprint. Discussion started: 14 December 2021

(c) Author(s) 2021. CC BY 4.0 License.

35 et al., 1999; Michel and Rignot, 1999; Yu et al., 2010; Gourmelen et al., 2011; Mouginot et al., 2019a). However, interferometry can be problematic over fast-flowing ice and/or areas where snow accumulation and melting occur due to rapid temporal decorrelation. In contrast, offset tracking (amplitude only) or speckle tracking (amplitude and phase) has been predominantly used in tracking both along-track and Line-of-Sight (LOS) ice motion as it is less sensitive to phase wrapping errors and temporal decorrelation (Fahnestock et al., 1993; Strozzi et al., 2002; de Lange et al., 2007; Strozzi et al., 2008; Nagler et al., 2012; Riveros et al., 2013; Fahnestock et al., 2016; Mouginot et al., 2017; Kusk et al., 2018).

There are several satellites derived regional ice velocity mappings that are released annually (Nagler et al., 2015; Mouginot et al., 2019b; Joughin, 2020a) or more frequently (Joughin, 2020b; Gardner et al., 2019; Solgaard et al., 2021). Among these efforts, the NASA MEaSUREs project Inter-mission Time Series of Land Ice Velocity and Elevation (ITS_LIVE) releases

45 ice velocity products (image-pair granules, data cubes and regional mosaics) with global coverage using temporally dense multi-sensor observations from both optical (Landsat 4/5/6/7/8 and Sentinel-2) and SAR (Sentinel-1) satellite data (Gardner et al., 2018). As described in (Lei et al., 2021a), the core processing algorithm of the ITS_LIVE project utilizes the combination of a precise geocoding module "Geogrid" and an efficient offset tracking module "autoRIFT" (autonomous Repeat Image Feature Tracking), both of which are open source (https://github.com/nasa-jpl/autoRIFT) and have been

50 integrated to NASA/JPL's InSAR Scientific Computing Environment (ISCE) software (https://github.com/isceframework/isce2).

In this work we focus on the ITS_LIVE processing of the C-band Sentinel-1A/B radar data. Specifically, we focus on the processing of the Terrain Observation with Progressive Scan (TOPS) mode of the Interferometric Wide Swath (IW) SAR 55 observations (De Zan and Guarnieri, 2006; Prats-Iraola et al., 2015; Miranda et al., 2017; Schubert et al., 2017). This mode enables surface imaging with a $3.7 \mathrm{~m}$ ground range and $15.6 \mathrm{~m}$ azimuth resolution with a repeat cycle of 6 days between A and B satellites. SAR imagery has qualities that are highly valuable to imaging of polar glaciers and ice sheets as the instrument is not obscured by cloud or limited by solar illumination. In Section 2.1, we provide an overview of the MEaSUREs ITS_LIVE Sentinel-1 Image-Pair Glacier and Ice Sheet Surface Velocities: Version 2, on which the ITS_LIVE

60 global ice velocity mosaics will be based. For illustration purposes, we show examples of several Sentinel-1 image pairs collected over Greenland (Lei et al., 2021b), and demonstrate several recent improvements to autoRIFT providing finer resolution, improved accuracy, and increased processing efficiency. In Section 2.2 we discuss the adoption of a $120 \mathrm{~m}$ regular-spaced output grid (previously a $240 \mathrm{~m}$ grid was used) with $50 \%$ overlap in search chips and a modified Normalized Displacement Coherence (NDC) filter. In Section 2.3 we discuss using a chip-size-dependent subpixel oversampling ratio

65 that improves sub-pixel accuracy while retaining computational efficiency. In Section 2.4 we present a runtime comparison between autoRIFT and ISCE software's default dense feature tracking algorithm, "dense ampcor". In Section 3 we discuss approaches to minimizing systematic geolocation errors (Section 3.1) and effects of ionosphere disturbance (Section 3.2). A summary of the work is provided in Section 4. 
https://doi.org/10.5194/essd-2021-393

Preprint. Discussion started: 14 December 2021

(c) Author(s) 2021. CC BY 4.0 License.

(c) (1)

\section{ITS_LIVE Sentinel-1 image pair product description and processing chain}

70 In this section we provide a high-level overview of the ITS_LIVE Sentinel-1 image pair product and the core processing algorithms. We do this by demonstrating both inputs to and outputs of the processing chain for a set of test data collected over Greenland. We then discuss two improvements to the autoRIFT processing chain that are exploited for Version 2 processing of the Sentinel-1 data.

\subsection{Product and methodology overview}

\section{2.1.1 Input dataset}

ITS_LIVE Sentinel-1 processing chain inputs and outputs are provided in Table 1.

Table 1. Input and output data for the MEaSUREs ITS_LIVE Sentinel-1 Image-Pair Glacier and Ice Sheet Surface Velocities: Version 2 processing chain. $\mathrm{x}$ and $\mathrm{y}$ are directions in map coordinates. Each output variable is accompanied with variable specific metadata.

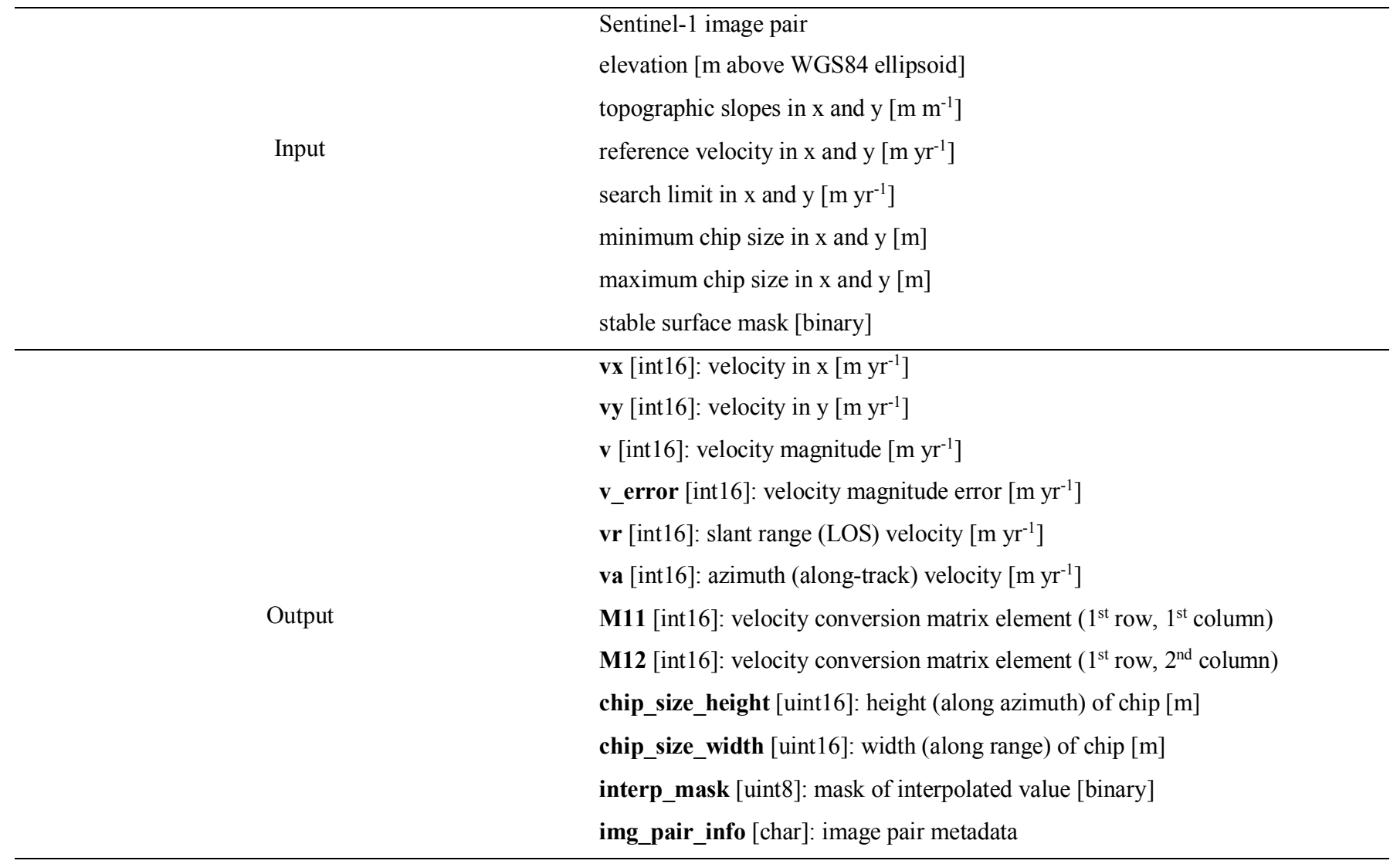




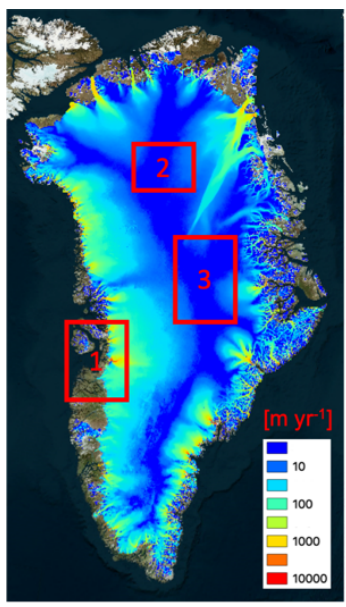

(a)

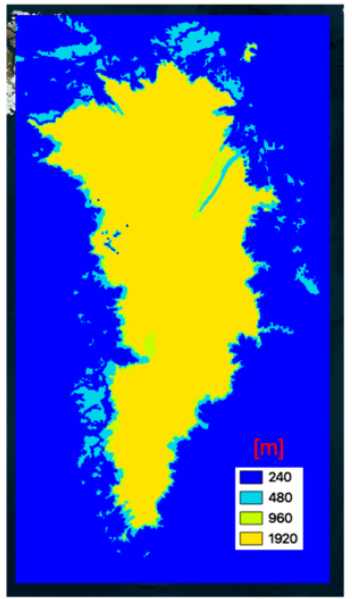

(d)

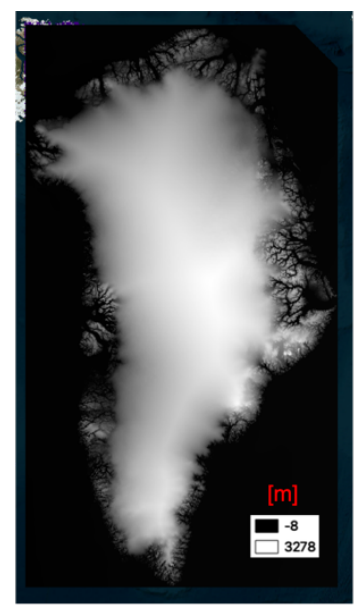

(b)

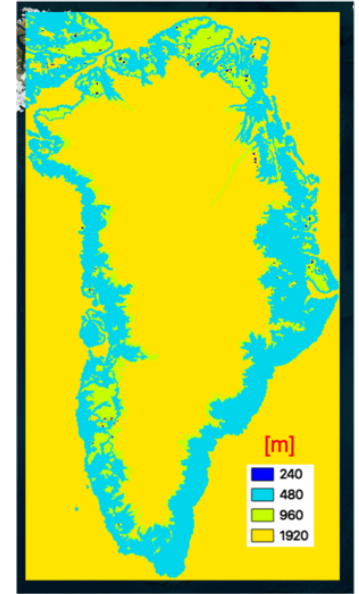

(e)

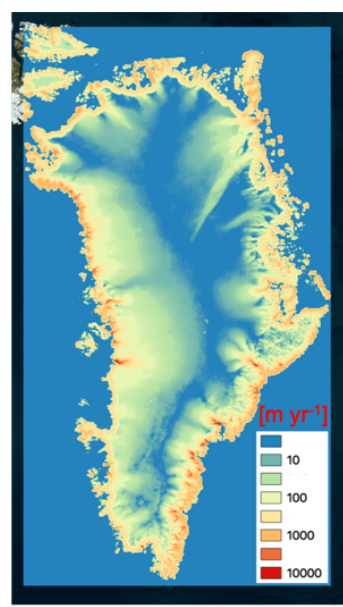

(c)

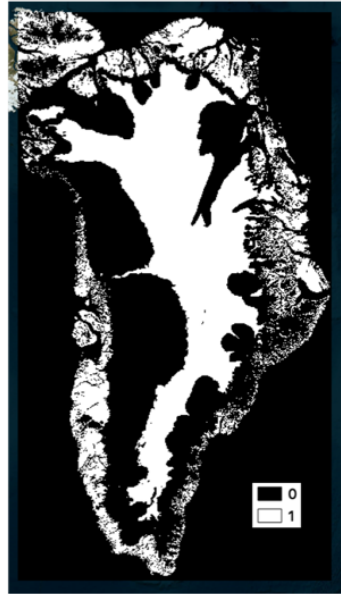

(f)

Figure 1: Input to the Sentinel-1 processing chain: (a) reference velocity magnitude with test sites shown as red rectangles, (b) elevation, (c) search limit in $x$, (d) minimum chip size, (e) maximum chip size, (f) stable surface mask, that is defined as ice free terrain or areas having a reference velocity $<15 \mathrm{~m} \mathrm{yr}^{-1}$.

85 Example input data for Greenland are illustrated in Fig. 1. In Fig. 1a, we demonstrate the magnitude of reference velocity from the 20-year ice-sheet-wide velocity mosaic (Joughin et al., 2010; Joughin et al., 2016) derived from the synthesis of SAR/InSAR data and Landsat-8 optical imagery. In ITS_LIVE processing, both the $\mathrm{x}$ - and $\mathrm{y}$-components of the reference velocity are needed to centre the downstream search routine. The three red rectangles in Fig. 1 show the locations used for demonstration and validation of the algorithms. The list of 21 Sentine-1 image pairs used for validation is provided in Table

902 (Lei et al., 2021b). In Fig. 1b, we show the GIMP Digital Elevation Model (DEM) for the Greenland Ice Sheet (Howat et al., 2014; Howat et al., 2015). The DEM, and its derivatives with respect to $\mathrm{x}$ - and y-directions, are all used to map between pixel index and displacement in radar range/azimuth coordinates and geolocation and surface velocity in map-projected Cartesian coordinates (Northings/Eastings). Note with a different DEM, the offset tracking estimates in radar coordinates 
https://doi.org/10.5194/essd-2021-393

Preprint. Discussion started: 14 December 2021

(c) Author(s) 2021. CC BY 4.0 License.

(c) (i)

(slant-range/azimuth) are relatively insensitive to DEM errors, e.g. a DEM change or error of a few tens of meters leads to

pixel mis-registration on the order of 0.001 pixels. However, the DEM-derived surface slopes that are used in mapping between radar viewing geometry and the map projected coordinate system are sensitive to the DEM error. Therefore, the map-projected velocity estimates tend to be affected by the DEM slope error (e.g. over regions with high topographic relief). The search limit is shown in Fig. 1c, which constrains the size of the search window and varies spatially with the reference velocity and proximity to the ocean. A search limit of zero indicates that no offset search should be conducted. Fig. 1d and

100 Fig. 1e are the minimum and maximum allowable chip sizes. autoRIFT will cycle from the minimum to the maximum chip size until a successful match is found, returning the finest achievable resolution within the specified limits. Here we specify smaller chip sizes for fast-flowing glaciers (lower accuracy with better resolution) along the margin of Greenland and larger chip sizes (better accuracy with lower resolution) for the interior regions where gradients in velocity are low (Fig. 1d-e). Fig. 1f shows the stable surface mask that is defined as ice free terrain or areas having a reference velocity $<15 \mathrm{~m} \mathrm{yr}^{-1}$ and is used 105 for calibration of the velocity fields.

Table 2. Sentinel-1 image pairs used for validation. All image pairs were acquired with the Interferometric Wide Swath (IW) Single Look Complex (SLC) mode. Only HH-pol is used. The pixel spacing is $3.67 \mathrm{~m}$ in ground range and $15.59 \mathrm{~m}$ in azimuth. The parenthesis of "(A/B)" denotes the Sentinel-1A image was acquired prior to the Sentinel-1B image, and vice versa.

\begin{tabular}{|c|c|c|c|}
\hline $\begin{array}{c}\text { Region } 1 \\
\text { (Path: } 90 \text { / Frame: 222, 227; } \\
\text { ascending) }\end{array}$ & $\begin{array}{c}\text { Region } 2 \\
\text { (Path: } 31 \text { / Frame: 253; } \\
\text { ascending) }\end{array}$ & $\begin{array}{c}\text { Region } 3 \\
\text { (Path: } 112 \text { / Frame: } 350 ; \\
\text { descending) }\end{array}$ & $\begin{array}{c}\text { Region } 3 \\
\text { (Path: } 31 \text { / Frame: 233, } \\
\text { 238; ascending) }\end{array}$ \\
\hline $20170104-20170110(\mathrm{~A} / \mathrm{B})$ & $20171226-20180101(\mathrm{~A} / \mathrm{B})$ & $20161002-20161008(\mathrm{~A} / \mathrm{B})$ & $20171226-20180101(\mathrm{~A} / \mathrm{B})$ \\
\hline $20170221-20170227$ (A/B) & 20161225-20161231 (B/A) & 20161231-20170106 (B/A) & \\
\hline $20170404-20170410(\mathrm{~B} / \mathrm{A})$ & 20181227-20190102 (B/A) & 20170331-20170406 (A/B) & \\
\hline $20170404-20170416(\mathrm{~B} / \mathrm{B})$ & & $20170711-20170717$ (B/A) & \\
\hline $20170404-20170422(\mathrm{~B} / \mathrm{A})$ & & $20170927-20171003(\mathrm{~A} / \mathrm{B})$ & \\
\hline $20170703-20170709(\mathrm{~A} / \mathrm{B})$ & & 20171226-20180101 (B/A) & \\
\hline \multirow[t]{4}{*}{$20171001-20171007$ (B/A) } & & $20180326-20180401(\mathrm{~A} / \mathrm{B})$ & \\
\hline & & 20180630-20180706 (A/B) & \\
\hline & & 20180928-20181004 (B/A) & \\
\hline & & 20181227-20190102 (A/B) & \\
\hline
\end{tabular}

110

All inputs were provided on a common $120 \mathrm{~m}$ grid in the NSIDC Sea Ice Polar Stereographic North projection (EPSG code 3413). This projection is used for all areas North of $55^{\circ} \mathrm{N}$ latitude. For areas South of $56^{\circ} \mathrm{S}$ latitude the Antarctic Polar Stereographic South (EPSG 3031) projection is used. For the rest of the world we use local Universal Transverse Mercator 
https://doi.org/10.5194/essd-2021-393

Preprint. Discussion started: 14 December 2021

(c) Author(s) 2021. CC BY 4.0 License.

(c) (i)

(UTM) projections. For all map projections, a constant grid posting of $120 \mathrm{~m}$ is used, while a $240 \mathrm{~m}$ posting was used for

115 Version 1.0 of the ITS_LIVE image pair products.

\subsubsection{ITS_LIVE Sentinel-1 Image-Pair Data Product}

The Version 2 ITS_LIVE Sentinel-1 image-pair data product (https://its-live.jpl.nasa.gov) features image-pair velocities at $120 \mathrm{~m}$ grid resolution generated from spaceborne SAR imagery, currently only using ESA's Sentinel-1 TOPS mode of the IW SAR observations. The products are created using the input dataset as introduced above in Section 2.1.1 and the feature tracking processing chain detailed in Section 2.1.3. Each data product consists of maps of land ice velocities over the spatial extent of the individual Sentinel-1 image pair at the specific epoch of data acquisition. The image-pair data product provides the finest resolution data for studying glacier change and serves as the base for the upcoming Version 2 ITS_LIVE data cube and mosaic products. Therefore, it is released as an independent data product to the end-users. All of the Sentinel-1A (launched April 3, 2014) and Sentinel-1B (launched April 25, 2016) image pairs with a maximum time separation of 60 days are processed into image-pair data products covering the globe within the Sentinel-1 latitude limits $\left(78^{\circ} \mathrm{S}\right.$ to $\left.81^{\circ} \mathrm{N}\right)$ that includes all land ice for the majority of large glacierized regions, dependent on data availability, quality, and for any given image-pair, offset tracking success. The extent of the image-pair encompasses the successful offset determinations for that pair. This means that two granules or image pairs with the same Sentinel-1 orbit/frame designations may have different extents depending on offset tracking success - if one of the input images was largely contaminated by temporal decorrelation

$130 \mathrm{and} /$ or atmospheric disturbance effects, then the extent to the output grid can be significantly reduced from the original image extents.

Image pair products span the time period from the launch date of the corresponding sensors (e.g., Sentinel-1A—Sentinel-1A image pairs are available after the Sentinel-1A launch date, Sentinel-1B-Sentinel-1B and Sentinel-1A-Sentinel-1B or

135 Sentinel-1B - Sentinel-1A image pairs are available after the launch date of Sentinel-1B) to present with a project goal of providing $<3$ months latency from the date of acquisition. Each of the above sensor combinations has its own merit, e.g., image pairs from the same sensor have negligible geolocation error and longer image-pair time separation (thus smaller uncertainty in velocity measurements), while the 6-day image pairs by combining the two sensors tend to be less sensitive to temporal decorrelation with more complete spatial extent but have large errors. Hence, the selection of the appropriate sensor 140 combination is dependent on the actual use case including data availability, quality, study area, and etc. The separation times for the image pairs vary from 6 to 60 days at a multiple of 6 days, which is also subject to data availability/quality over each study area. All the output variables were provided on the same $120 \mathrm{~m}$ grid in the same map projection as the input dataset detailed above in Section 2.1.1. The effective spatial resolution in offset tracking spatially varies with the progressive search chip size (Fig. 1d-e; from $240 \mathrm{~m}$ to $1920 \mathrm{~m}$ ), where fast-flowing glaciers are characterized by smaller chip sizes (less

145 accuracy but finer resolution, e.g. $240 \mathrm{~m}$ ), and the stable or slow-flowing ice uses larger chip sizes (lower resolution but higher accuracy, e.g. $1920 \mathrm{~m}$ ). 
The output data (Table 1) are packaged in a single NetCDF, using Climate Forecast (CF) Version 1.6 conventions. Individual NetCDF files range between $5 \mathrm{MB}$ and $15 \mathrm{MB}$ in size. The $\mathrm{x}$ and y velocities (vx and vy), velocity magnitude (v) and its error (v_error), and chip_size_height, chip_size_width, interp_mask, and img_pair_info are standard output for all ITS_LIVE image-pair products (i.e. both optical and radar). The rest of the output are specific to radar data, such as the slant-range (LOS) and azimuth (along-track) velocities (vr and va) that are provided in native radar viewing geometry. LOS parameters (M11 and M12) are provided in the output for each image pair to facilitate the inversion for x/y horizontal velocity when using two independent slant-range measurements (i.e. one ascending image pair and one descending image pair). This is useful to correct for ionosphere disturbance effects on the azimuth offset. This approach is discussed in Section 3.2 .

Velocities are calculated from imagery that has been map projected. This can introduce scale errors of up to a few percent that are dependent on the projection used and the location of the imagery. Unlike correcting the scale distortion in Version 1 ITS_LIVE products, for Version 2 ITS_LIVE products (both radar and optical), the scale distortion due to calculating velocities from map projected imagery will not be corrected for. The implications of this is detailed further in the Version 2 documentation.

\subsubsection{Processing chain}

The Sentinel-1 Single Look Complex (SLC) image pairs are pre-processed using the ISCE software prior to dense offsettracking, where the two SLC images are precisely co-registered using the satellite orbit geometry. Dense offset-tracking relies heavily on two Python modules: Geogrid and autoRIFT, followed by a NetCDF packaging program (all of which are open access and available at https://github.com/nasa-jpl/autoRIFT). As described by Lei et al. (2021a), the Sentinel-1 orbit information is used by Geogrid to transform all of the input parameters listed in Table 1 from map-projected Cartesian coordinates (Northing/Easting) into radar range/azimuth coordinates (pixel index and displacement). The inputs are translated to radar coordinates but not resampled (remains in original $120 \mathrm{~m}$ grid). Inputs are cropped to the spatial extent of

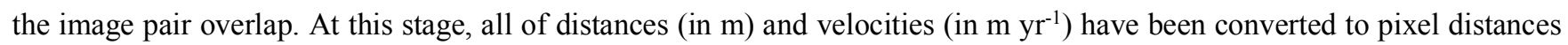
in range/azimuth, where velocities are multiplied by the time separation between images to convert from a rate to a distance. The approach of defining a regular output grid in map-projected coordinates and then converting to an irregular grid in radar coordinates is somewhat unique, yet powerful. The approach avoids the need for any reprojection of the imagery or resampling of the derived velocity fields when moving between radar and map coordinates. This eliminates costly interpolation, and resulting artifacts, in the final product.

Once inputs (Table 1) have been mapped/converted to radar coordinates/units they are passed to the autoRIFT module that preforms the dense range and azimuth offset search between the two images. autoRIFT finds the displacement between two 
180 images using a nested grid design, sparse/dense combinative searching strategy, and disparity filtering technique that result in significant performance gains and that are detailed in Gardner et al. (2018) and Lei et al. (2021a). autoRIFT then cycles from the minimum to the maximum chip size (Fig. 1d-e) until a successful match is found, returning the value of the first valid offset (finest resolution). Each progressive chip size is a factor of 2 larger than the previous and is solved on a geographic grid that satisfies a $50 \%$ overlap between adjacent search chips of the same size (i.e. $240 \mathrm{~m} \times 240 \mathrm{~m}$ chip is

185 solved on a constant $120 \mathrm{~m}$ grid, a $480 \mathrm{~m} \times 480 \mathrm{~m}$ chip is solved on a constant $240 \mathrm{~m}$ grid). This change in sample rate is termed a "nested grid" design. autoRIFT employs the NDC filter to distinguish valid matches from random noise. Earlier versions of autoRIFT did not permit overlap between adjacent search chips. To accommodate overlapping chips adjustments were made to the NDC filter parameters and are detailed in Section 2.2. For each chip size used, a sparse search (1/8 sample rate) is performed to identify and exclude areas of decorrelation (low coherence). A dense search is then performed for all

190 valid areas at the full sample rate, with search center and range informed by the results of the sparse search. This sparse/dense combinative searching strategy substantially improve computational efficiency. autoRIFT further improves efficiency without sacrificing accuracy or resolution by employing: OpenCV's C++ functions for Normalized CrossCorrelation (NCC), a downstream search routine to reduce the search range, subpixel offset estimation using a Gaussian pyramid upsampling algorithm and, various high-pass filtering options to pre-process the image pair with data compression

195 (Gardner et al. 2018; Lei et al. 2021a). In Section 2.3 we describe the addition of chip size dependent subpixel oversampling ratios that further enhance performance.

Sentinel-1 range and azimuth offset estimates are then calibrated for the subswath- and full swath-dependent geolocation errors that are identified for Sentinel-1A/B combinations which are affected by an inter-satellite systematic bias (Section 3.1).

200 Offsets are then converted back to map-projected coordinates/units using Geogrid. All of the output data (Table 1) are packed as a NetCDF with accompanying metadata.

\subsection{Fine output grid with improved NDC filter}

One key component of autoRIFT that identifies and removes poor feature matches is the implementation of the NDC filter. In this section, we document updates to the NDC filter for handling finer grid spacings with overlapping search chips. As

205 illustrated in Fig. 2a, the original NDC filter assumed that there was no overlap between adjacent chips, thus independent of each other. However, when oversampling is desired, adjacent chips overlap (e.g. Fig. $2 \mathrm{~b}$ shows the case of $50 \%$ overlap). This results in information being shared between neighbouring search chips, changing the Signal-to-Noise Ratio (SNR) statistics. For this reason, we modified the NDC filter parameters to account for the change in SNR statistics. 


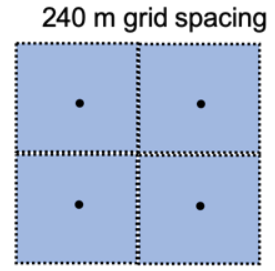

(a)

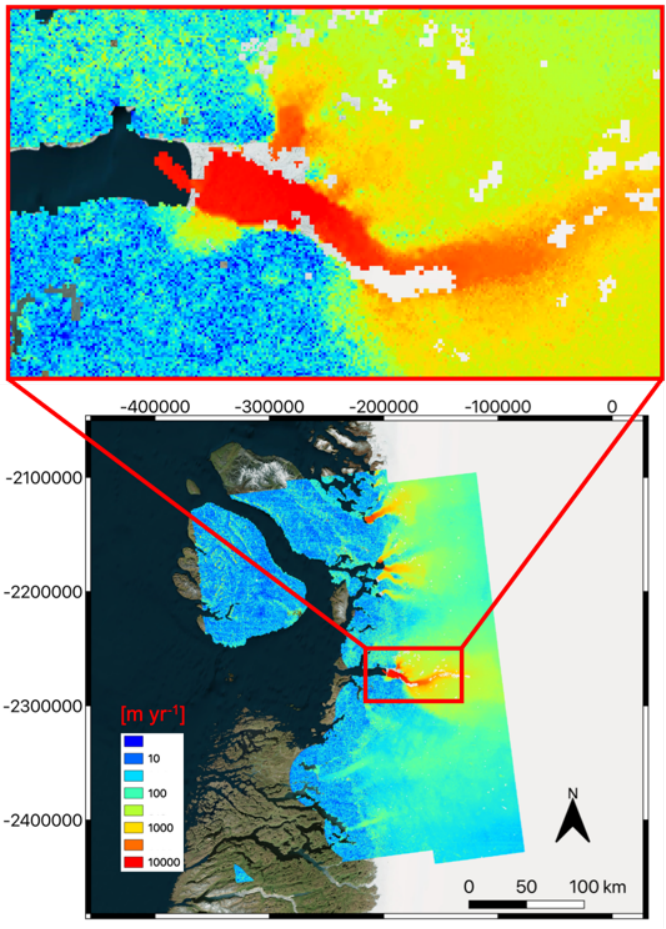

(c)
$120 \mathrm{~m}$ grid spacing

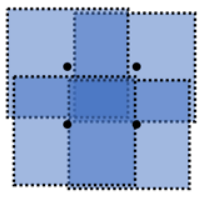

(b)

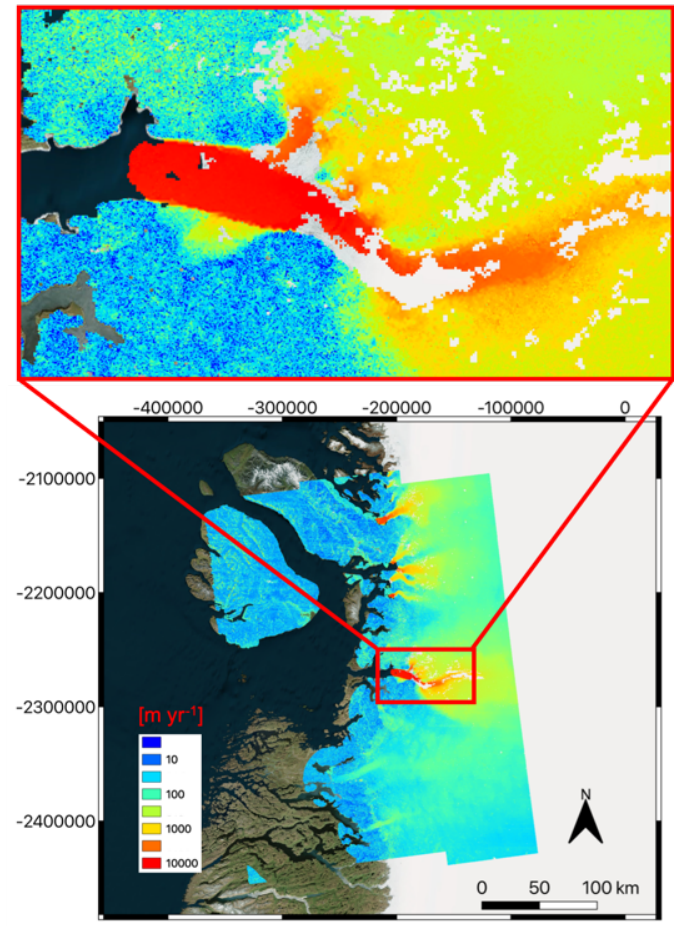

(d)

Figure 2: Comparison between $240 \mathrm{~m}$-spacing grid and $120 \mathrm{~m}$-spacing grid: (a) $240 \mathrm{~m}$ grid with non-overlapping search chips, (b) $120 \mathrm{~m}$ grid with $50 \%$ overlapping search chips, (c) autoRIFT-estimated ice velocity magnitude for $240 \mathrm{~m}$ grid, (d) autoRIFTestimated ice velocity magnitude for $120 \mathrm{~m}$ grid. The same minimum chip size of $240 \mathrm{~m}$ is used for both cases. For (c) and (d), the Sentinel-1 image pair 20170404-20170410 is used in Region 1 (with the closeup at the Jakobshavn Isbra glacier).

215 As first developed in (Gardner et al., 2018) and also described in (Lei et al., 2021a), the NDC filter in autoRIFT identifies and removes low-coherence displacement results based on displacement disparity thresholds that are normalized to the local search distance. This is done to normalize changes in the amplitude of the noise that scales linearly with the search distance. The NDC filter is defined with a few filter parameters: FracValid (fraction of valid grid points within the filter window size; default is $8 / 25$, e.g. 8 valid points for a $5 \times 5$ filter window), FracSearch (fraction of displacement disparity normalized to search distance; default is 0.2), FiltWidth (filter window size; default is 5), Iter (number of iterations that the filter is applied; default is 3) and MadScalar (multiplicative factor for thresholding the displacement disparity; default is 4). The 
NDC filter is applied as a sliding window filter. For an example of $5 \times 5$ filter window size, the workflow of the NDC filter is summarized as below:

a. Normalize the displacement estimates by the search distance;

b. Compute the normalized displacement disparity in reference to the central grid point of the filter window and count the number of grid points that have displacement disparity greater than the filter parameter FracSearch;

c. If the number of grid points in the above step is greater than or equal to FracValid $\times$ FiltWidth ${ }^{2}(8$ in this case), the central grid point is retained; otherwise, it is discarded;

d. A second condition check is then performed: The central grid point is retained if the deviation of its displacement from the median value of this filter window is less than the Median Absolute Deviation (MAD) multiplied by MadScalar. [This step is repeated for Iter times for the entire displacement field by discarding poor offset matches in each iteration].

e. If all the above conditional checks are passed, the central grid point is retained; otherwise, it is discarded.

235 The filter parameters need to be adjusted when there is overlap between adjacent chips to maintain the same filter performance as in the non-overlap scenario. For the 50\% overlap case illustrated in Fig. 2b, the default FracSearch value of 0.2 can be used but FracValid needs to be made larger due to the inter-dependence of neighbouring offsets. As an extreme case, with $0 \%$ overlap, FracValid should be the same as the default value for the non-overlap case; with $100 \%$ overlap, FracValid should be 1. Therefore, considering these extreme cases, and through trial and error, we found that the following formula works well for all cases considered:

FracValid $_{\mathrm{w}_{-} \text {overlap }}=$ FracValid $_{\text {wo_overlap }} \times(1-$ overlap $)+$ overlap $^{2}$,

where FracValid w_overlap $_{\text {and FracValid }}$ wo_overlap are the FracValid parameters with and without overlap, and overlap is the percentage of the overlap (e.g. 50\% in Fig. 2b). Since the adjacent grid points share information, the filter window size needs to be enlarged by a factor of 1/overlap in order to have an equivalent number of independent samples within a filter 245 window:

FiltWidth ${ }_{\mathrm{w} \_ \text {overlap }}=\operatorname{round}\left[\left(\right.\right.$ FiltWidth $\left._{\text {wo_overlap }}-1\right) /$ overlap +1$]$,

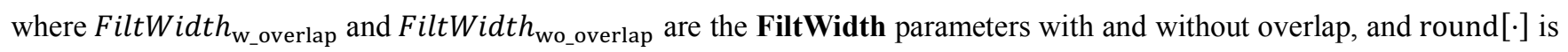
the round to integer operation. Using Eq. (1) and (2), the NDC filter performance for the overlapping chips is comparable to the non-overlap scenario. Fig. 2c demonstrates the ice velocity magnitude from the Sentinel-1 image pair 2017040425020170410 centered over the Jakobshavn Isbræ glacier in Region 1 (Fig. 1a) using the earlier 240 m-posting grid with nonoverlapping search chip of size $240 \mathrm{~m}$ (Fig. 2a). Fig. 2d shows results for the $120 \mathrm{~m}$-posting grid using a search chip of size $240 \mathrm{~m}$ with $50 \%$ overlap between adjacent search chips (Fig. 2b). From the results in Fig. 2c-d, it can be seen that the region of interest (ROI) between the two cases are very similar, implying the comparable filter performance, while the $120 \mathrm{~m}$ grid indeed provide higher resolution estimates without sacrificing SNR over the ROI. 
https://doi.org/10.5194/essd-2021-393

Preprint. Discussion started: 14 December 2021

(c) Author(s) 2021. CC BY 4.0 License.

(c) (i)

\subsection{Search-chip-size dependent subpixel oversampling ratio}

autoRIFT identifies the integer offset between two images as the maximum NCC value for all possible locations of the search chip (subset of image 2) within the search window (subset of image 1). To identify the subpixel component of the offset, an oversampled surface is fit to the pixel NCC values to create a smooth surface from which the subpixel offset can be estimated. Careful consideration must be taken on how the surface is fit, as some approaches can lead to biases in offset estimates (Stein et al., 2006). To minimize such bias, autoRIFT employs a Gaussian pyramid upsampling algorithm. Surface fitting is computationally expensive, increasing substantially with the oversampling ratio. Therefore, a matching needs to be achieved between the maximum precision achievable by the underlying data and the optimal oversampling ratio. An oversampling ratio that is too coarse will result in less precise data, while an oversampling ratio that is too fine will result in unnecessary computational overhead. In addition, there is an inherent relationship between the size of the search chip and the maximum achievable precision; lager chip size results in higher achievable precision and vice versa. Therefore, it is desirable to select an optimal trade-off between efficiency and the precision of the subpixel oversampling ratio as a function of chip size, as in Lei et al. (2021a).

We consider four chip sizes: $240 \mathrm{~m}, 480 \mathrm{~m}, 960 \mathrm{~m}$ and $1920 \mathrm{~m}$, and four subpixel oversampling ratios: 1/16, 1/32, 1/64 and 1/128. To investigate the relation between chip size dependent accuracy and oversampling ratio we select the Sentinel-1 image pair 20171226-20180101 in Region 2. Region 2 represents slow-moving ice surface with no detectable gradient in flow and all four chip sizes result in valid offset tracking results. Results determined using an oversampling ratio of 1/128 are considered most precise. Fig. 3 shows the x-velocity (vx) for various chip sizes using an oversampling ratio of 1/128. Note that the subswath bias (visible at swath boundaries) with azimuth streaks that are noticeable in Fig. 3 are due to the

275 Sentinel-1 systematic geolocation error and ionosphere delay effects, which are discussed and accounted for using the methods presented in Section 3. From Fig. 3 it can be seen that smaller chip sizes ( $240 \mathrm{~m}$ and $480 \mathrm{~m}$ ) have a high standard deviation (noise), while larger chip sizes $(960 \mathrm{~m}$ and $1920 \mathrm{~m}$ ) have lower standard deviation (more precise) in the displacement estimates. The question we now try to answer is: is the computational cost of a finer oversampling ratio justified by an improvement in precision? To determine this balance, we examine changes in the standard deviation as a function of oversampling ratio for each chip size. A summary of the results is provided in Table 3.

Table 3. Selection of subpixel oversampling ratio for various chip sizes. The first four rows show the results for the highest oversampling ratio $(1 / 128)$ which is used to characterize the maximum achievable precision. The last four rows show the results for the lowest oversampling ratio that provides negligible degradation (1-3\%) in precision. The column of "nearest oversampling ratio" is selected to match the maximum achievable precision and thus determine the optimal oversampling ratios to be used for each chip size (first column of the last four rows).

\begin{tabular}{|c|c|c|c|c|}
\hline Oversampling Ratio & Chip Size [m] & Runtime [sec] & $\mathrm{x} / \mathrm{y}$ precision [pixel] & Nearest oversampling ratio \\
\hline
\end{tabular}


https://doi.org/10.5194/essd-2021-393

Preprint. Discussion started: 14 December 2021

(c) Author(s) 2021. CC BY 4.0 License.

\begin{tabular}{ccccc}
\hline $1 / 128$ & 1920 & 52.9 & $0.0086 / 0.0097$ & $1 / 128 \approx 0.0078$ \\
$1 / 128$ & 960 & 83.5 & $0.0118 / 0.0122$ & $1 / 128 \approx 0.0078$ or $1 / 64 \approx 0.0156$ \\
$1 / 128$ & 480 & 200.8 & $0.0155 / 0.0185$ & $1 / 64 \approx 0.0156$ \\
$1 / 128$ & 240 & 661.5 & $0.0321 / 0.0392$ & $1 / 32=0.0312$ \\
\hline $1 / 128$ & 1920 & 52.9 & $0.0086 / 0.0097$ & - \\
$1 / 128$ & 960 & 83.5 & $0.0118 / 0.0122$ & - \\
$1 / 64$ & 480 & 110.4 & $0.0158 / 0.0188$ & - \\
$1 / 32$ & 240 & 188.1 & $0.0332 / 0.0401$ & - \\
\hline
\end{tabular}

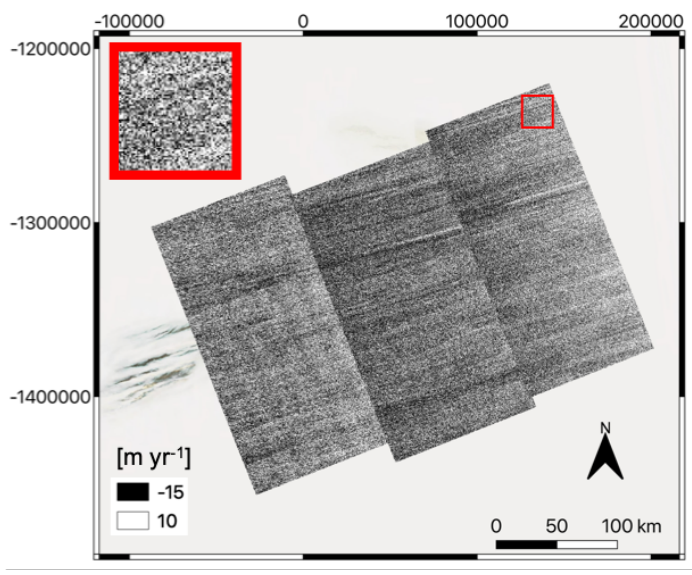

(a)

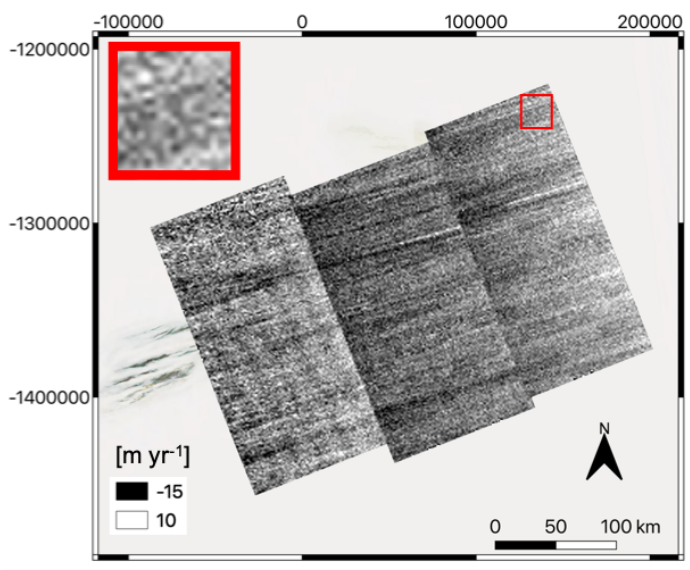

(c)

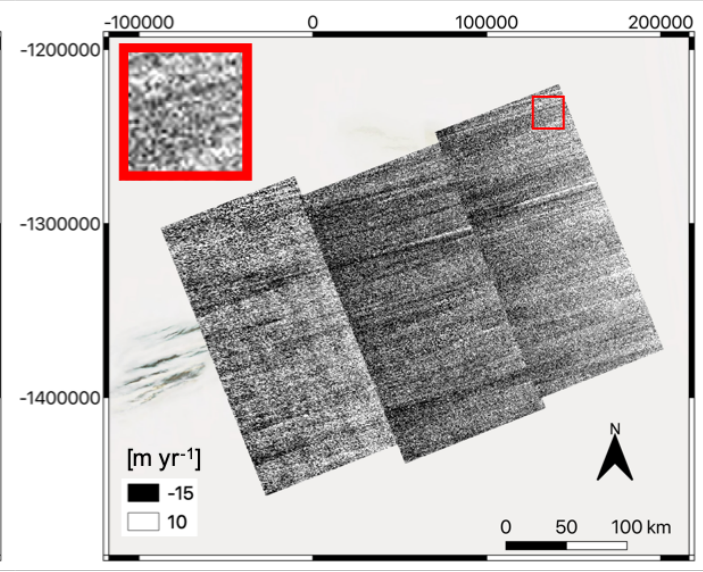

(b)

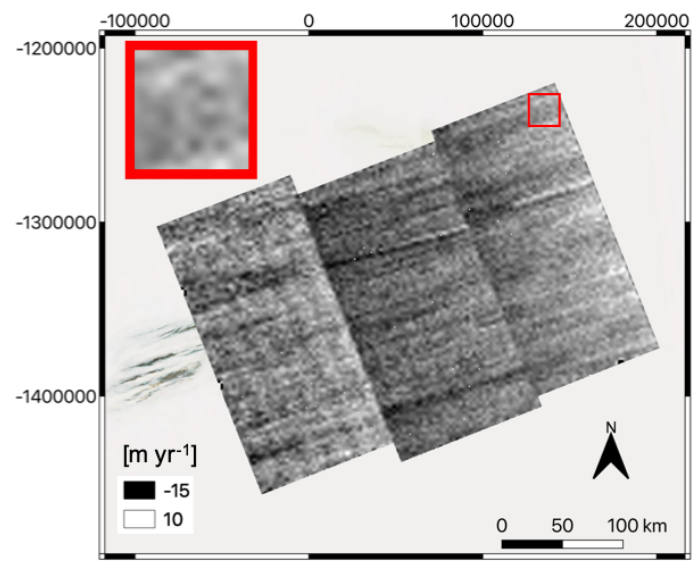

(d)

Figure 3: x-velocity from offset tracking using a chip size of: (a) $240 \mathrm{~m}$, (b) $480 \mathrm{~m}$, (c) $960 \mathrm{~m}$, and (d) $1920 \mathrm{~m}$. The same subpixel oversampling ratio of $1 / 128$ is used for all cases. The Region 2 Sentinel-1 image pair 20171226-20180101 is used. 
https://doi.org/10.5194/essd-2021-393

Preprint. Discussion started: 14 December 2021

(c) Author(s) 2021. CC BY 4.0 License.

(c) (i)

From our analysis we find that a coarser oversampling ratio of $1 / 32$ and $1 / 64$ for a chip size of $240 \mathrm{~m}$ and $480 \mathrm{~m}$, respectively, results in a modest increase in noise $(<3 \%)$ with up to a factor of 3 improvement in performance (Table 3 ). We therefore select these oversampling ratios for the smaller chip sizes. For a chip size of $960 \mathrm{~m}$ and $1920 \mathrm{~m}$ we see a substantial (30\% for $960 \mathrm{~m}$ and $80 \%$ for $1920 \mathrm{~m}$ ) increase in noise with a decrease in oversample ratio (1/64). Therefore, we

295 select an oversample ratio of $1 / 128$ for these larger chip sizes. This intelligent oversampling ratio is adopted in autoRIFT for generating the ITS_LIVE Sentinel-1 offset tracking products. The optimal oversampling ratio is dependent on the information content of the input imagery and would require a similar analysis, as conducted here, for application to other satellite missions. For Landsat- 8 data autoRIFT uses an oversampling ratio of 1/16, 1/32, 1/64 and 1/64 for chip sizes of 240 m, $480 \mathrm{~m}, 960 \mathrm{~m}$ and $1920 \mathrm{~m}$, respectively. A coarser oversampling ratio leads to lower precision velocity outputs. This can

300 be seen when plotting chip size dependent histograms of va and vr in which values will be clustered according to the oversampling ratio. A smoother histogram can be achieved with a finer oversampling ratio but due to the limitations of the data a finer oversampling ratio will not achieve higher accuracy. Precision and accuracy can be increased through postprocessing of the data (e.g. spatial or temporal smoothing).

\section{4 autoRIFT runtime analysis}

305 As previously shown by Lei et al. (2021a), autoRIFT outperforms the widely-used "dense ampcor" feature tracking algorithm that is the default feature tracker included in NASA/JPL's ISCE software, with two orders of magnitude improvement in efficiency and $>20 \%$ improvement in accuracy. Here we expand on the apples-to-apples comparison between autoRIFT and ampcor that was conducted by Lei et al. (2021a). We use 7 Region 1 Sentinel-1 image pairs with the same autoRIFT and ampcor setting as used by Lei et al. (2021a: Table 3). The runtime and accuracy improvements of autoRIFT compared to ampcor are illustrated in Fig. 4 as a function of the \% valid ROI (i.e. the $\%$ of valid pixels returned by autoRIFT). In Fig. 4a, an exponential function was fit to the runtime data points with respect to ROI. The figure shows that autoRIFT is about 150 times faster than ampcor for Sentinel-1 image pairs with high correlation between images (large ROI) and up to 208 times faster when there is low correlation between images (low ROI). This increase in runtime improvement with a decrease in ROI is due to autoRIFT's sparse search that excludes areas of low correlation before executing a dense

315 search. Regarding the accuracy of both feature trackers, we refer to the standard deviation of $\mathrm{x} / \mathrm{y}$ pixel displacements over stable surfaces (Fig. 1f). Since dense ampcor does not employ any filtering to remove bad matches, we calculated the error of dense ampcor results wherever autoRIFT produced reliable estimates. As shown in Fig. 4b, autoRIFT provides an improvement in accuracy on the order of $20-50 \%$ (33\% when averaged across all 7 image pairs). Some of the improvement can be attributed to autoRIFT's ability to narrow the search range of the dense search based on information gained from the sparse search (a form of regularization). Different approaches to locating the subpixel displacement may also contribute autoRIFT's improved accuracy (e.g. Gaussian pyramid upsampling algorithm). 


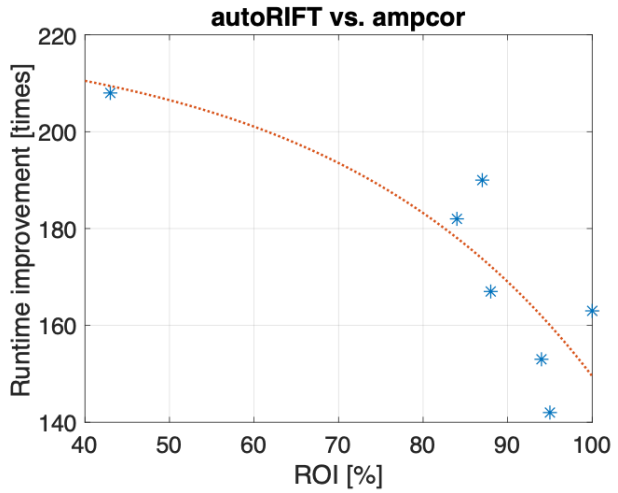

(a)

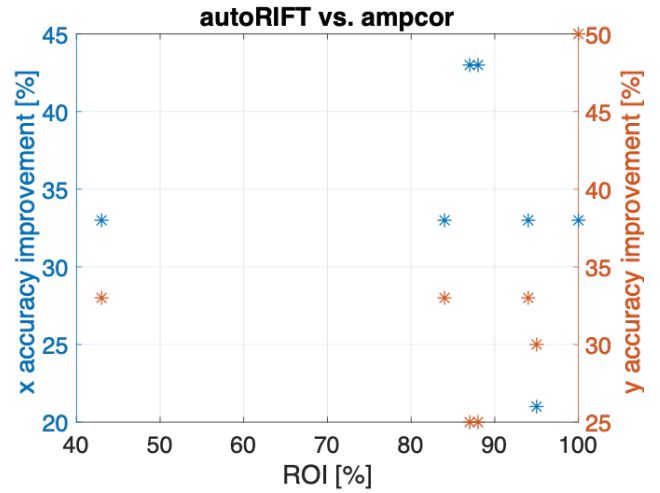

(b)

Figure 4: Apples-to-apples comparison between autoRIFT and ampcor: (a) runtime improvement, (b) x/y accuracy improvement. Both autoRIFT and ampcor use the same setting for offset tracking as in Lei et al. (2021a): chip size of $64 \times 64$, grid spacing of $64 \times$ 64, and search limit of $62 \times 16$. The 7 Sentinel-1 image pairs in Region 1 (Frame 222 only) are used.

\section{ITS_LIVE Sentinel-1 image pair product calibration and error correction}

In this section we demonstrate approaches to calibrate and correct for errors in the ITS_LIVE Sentinel-1 image pair product. Section 3.1 discusses the systematic geolocation error calibration (both subswath- and full swath-dependent). In Section 3.2, we introduce a method of correcting for the ionosphere disturbance effects that contaminate radar azimuth measurements, which uses the radar LOS measurements from two image pairs with differing acquisition geometries (i.e. ascending and descending).

\subsection{Geolocation error calibration}

As pointed in Gisinger et al. (2021), Sentinel-1's azimuth Doppler Frequency Modulation (FM) rate can be offset compared

with the modelled value for each of the three subswaths in the TOPS acquisition mode because of the use of constant terrain height for FM rate computation for extended areas of observed terrain (spatial extent of the SAR image). In reality, each of the three subswaths has its own azimuth FM rate. This systematic mismatch can cause both swath-dependent and subswathdependent pixel shift (geolocation error) along the radar azimuth direction when focusing radar signals. Full swath- and subswath-dependent systematic geolocation errors along the radar range direction also result from the bistatic nature of the antenna, i.e., transmitting and receiving are not simultaneous, which is neglected in the current SLC processing and thus introduces a residual Doppler shift error when focusing the radar pulses in the range direction (Gisinger et al., 2021). Several studies (Gisinger et al., 2021; Solgaard et al., 2021; Schubert et al., 2017) have investigated the full swath-dependent range/azimuth geolocation error of Sentinel-1 IW products, and also mentioned the existence of the subswath-dependent geolocation error. At the time of writing, we are not aware of any existing subswath-dependent geolocation error correction. 
https://doi.org/10.5194/essd-2021-393

Preprint. Discussion started: 14 December 2021

(c) Author(s) 2021. CC BY 4.0 License.

(c) (1)

345 In the following subsections we demonstrate the calibration of both types of geolocation error for the ITS_LIVE Sentinel-1 ice velocity products.

\subsubsection{Subswath-dependent geolocation error}

When working with Sentinel-1 image pairs, systematic geolocation errors cancel out in the resulting offset maps when using data from the same sensor (both from Sentinel-1A or both from Sentinel-1B); however, this is not the case when using a combination of the two (one from Sentinel-1A and the other from Sentinel-1B). For this reason, we focus on corrections that need to be applied when image pairs are composed of images from differing sensors.

As mentioned in Section 2.3 (Fig. 3), there is subswath-dependent velocity bias between the three subswaths. We illustrate this effect by showing both the raw slant-range and azimuth velocity products (vr and va from Table 1) in Fig. 5a-b for the

355 Sentinel-1 pair 20171226-20180101 in Region 2, where the range-dependent variation of the velocity (by averaging each range line/bin) is found in Fig. 5c. Fig. 5c clearly demonstrates the subswath mismatch. To correct for the subswath mismatch, we select two areas in the interior of Greenland (Region 2 and 3) with 14 Sentinel-1A/B image pairs (in Table 2) that contain small and smooth gradients in ice motion and ionospheric effects, and are thus more suitable for calibration of errors. Only 11 out of the 14 pairs are eventually shown in Fig. 6 after eliminating 3 noisy pairs contaminated by strong 360 ionosphere scintillation (Jiao et al., 2013). We calculate the inter-subswath bias by differencing the median values on either side of the subswath boundaries of the slant-range and azimuth offset. The results of this analysis are shown in Fig. 6.

From Fig. 6, the average offset bias between subswath 2 and 1 are -0.010 pixel (slant-range) and 0.019 pixel (azimuth), while the estimates for subswath 3 and 2 are -0.007 pixel (slant-range) and 0.006 pixel (azimuth), which uses the pair convention of Sentinel-1A being acquired prior to Sentinel-1B. These inter-subswath bias estimates are used in generating our ITS_LIVE Sentinel-1 image pair products for calibrating the subswath-dependent geolocation error. The performance of the correction is illustrated in Fig. 5d-f as well, where both the velocity maps and the range-dependent variation curve show greatly improved matching between subswaths (i.e. there is little to no step change in velocity when transitioning between subswath boundaries). 


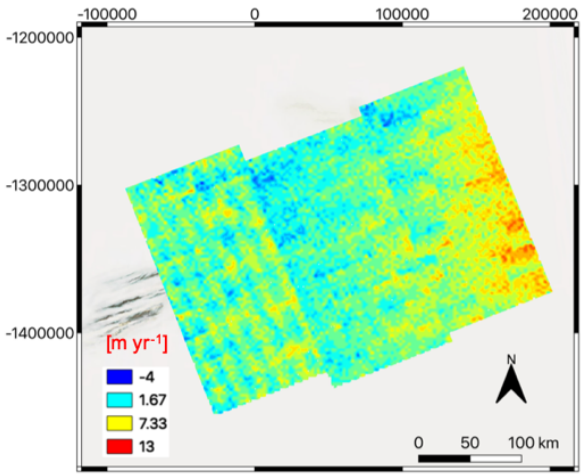

(a)

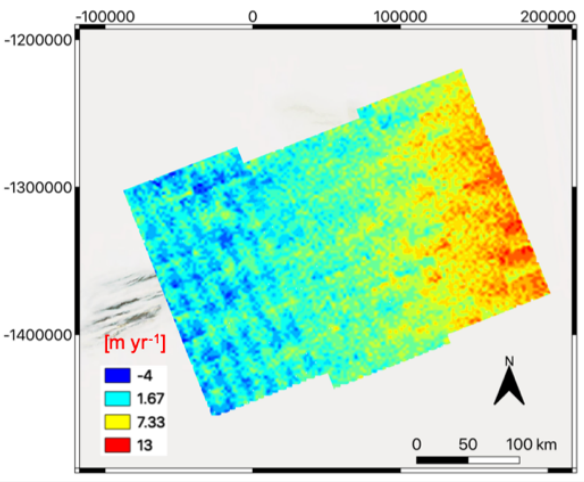

(d)

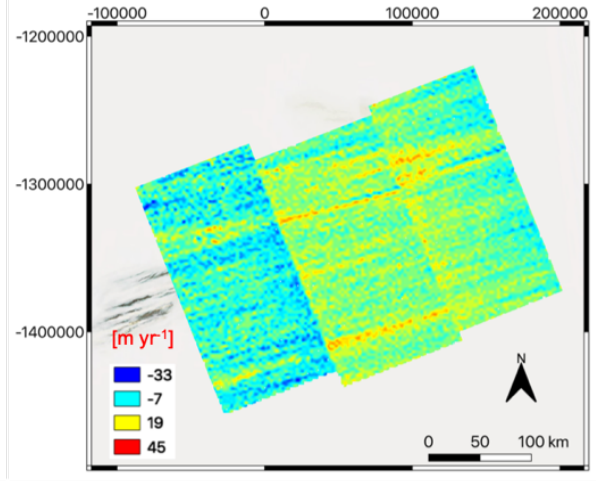

(b)

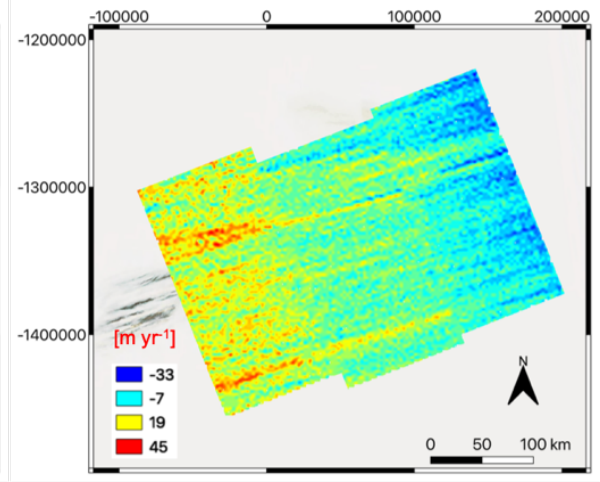

(e)

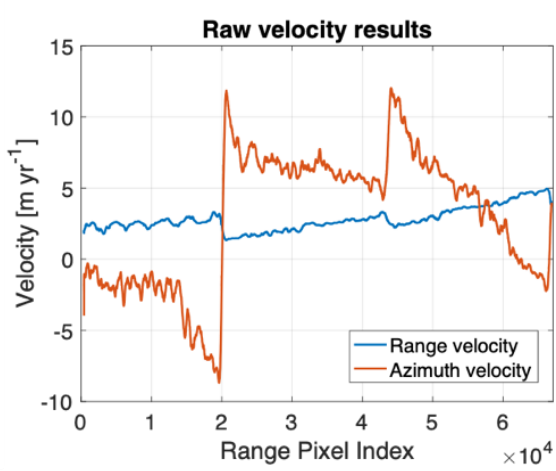

(c)

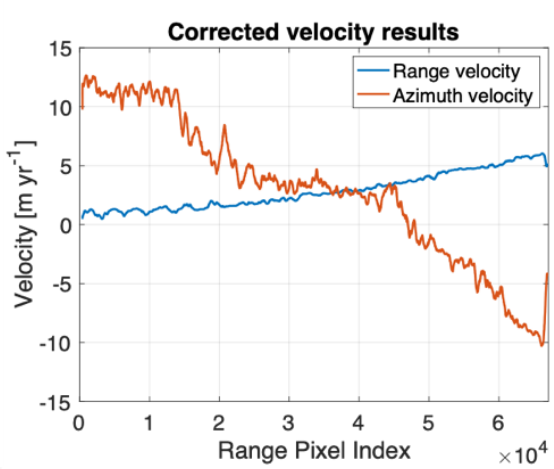

(f)

Figure 5: Illustration of subswath-dependent geolocation error and calibration: (a) raw slant-range velocity, (b) raw azimuth velocity, (c) range-dependent variation of raw velocity (averaged for each range line/bin), (d) corrected slant-range velocity, (e) corrected azimuth velocity, (f) range-dependent variation of corrected velocity (averaged for each range line/bin). The Sentinel-1 image pair 20171226-20180101 in Region 2 is used here.

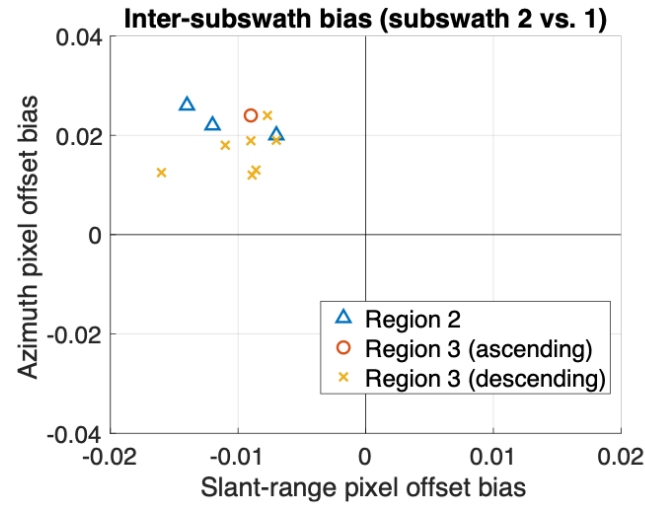

(a)

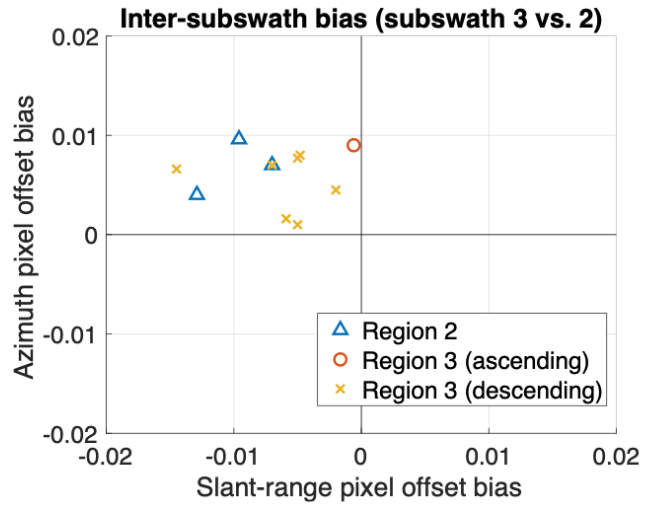

(b)

Figure 6: Inter-subswath bias of slant-range and azimuth offsets: (a) subswath 2 versus 1 , (b) subswath 3 versus 2 . The 11 Sentinel-1A/B image pairs in Region 2 and Region 3 are shown here. 
https://doi.org/10.5194/essd-2021-393

Preprint. Discussion started: 14 December 2021

(c) Author(s) 2021. CC BY 4.0 License.

(c) (i)

\subsubsection{Full swath-dependent geolocation error}

After the subswath-dependent geolocation error correction is applied, we apply additional corrections to remove full swathdependent errors. As reported in previous studies (Gisinger et al., 2021; Solgaard et al., 2021; Schubert et al., 2017), the geolocation error for the full swath can be measured by comparing the SLC image pixel geolocations or resulting offsettracking velocity to ground control points, e.g., array of corner reflectors or bedrocks. Locally determined estimates can then be applied to all the Sentinel-1 image pairs as a static calibration assuming that the error is systematic in nature. Conceptually, this calibration is similar to referencing an interferogram to a known reference point (e.g. GPS station) in InSAR analysis. In this paper, we adopt the similar approach but apply a unique correction to each Sentinel-1 image pair, by separately calibrating to any overlapping stable surfaces, as has been done in our previous work (Gardner et al., 2018; Lei et al., 2021a). We determine the calibration surface using a "stable surface" mask (Fig. 1f) that is defined as any area consisting of ice-free terrain and/or slow-moving ice defined using an a-priori reference velocity $\left(<15 \mathrm{~m} \mathrm{yr}^{-1}\right.$ : Fig. 1f). When imagepair offsets do no intersect any valid "stable surface" we calibrate the slowest $25 \%$ (defined by a-priori velocity) velocity magnitude to an a-priori reference velocity. We examine the performance of these two approaches for full swath-dependent geolocation error calibration using all 20 Sentinel-1A/B image pairs (Table 2) in Region 1, 2 and 3. Results are illustrated in Fig. 7.

The mean "stable surface" mask calibrated velocity bias is $-4.07 \mathrm{~m} \mathrm{yr}^{-1}$ in slant range and $-26.81 \mathrm{~m} \mathrm{yr}^{-1}$ in azimuth using the pair convention of Sentinel-1A being acquired prior to Sentinel-1B with a 6-day time separation. Note that in this paper, we report the velocity calibration bias (rather than pixel offset bias in Section 3.1.1 or offset bias in meters) for the full-swathdependent geolocation error, in order to better compare with the values reported in the literature as shown below. One can convert from one to another by using the 6-day time separation and/or slant-range/azimuth pixel size. Using the slowest $25 \%$ velocities, the mean velocity bias estimated to be $-4.01 \mathrm{~m} \mathrm{yr}^{-1}$ in slant range and $-27.09 \mathrm{~m} \mathrm{yr}^{-1}$ in azimuth. Hence, by using a stable surface mask (which is available in most regions) or the slowest $25 \%$ velocities, our dynamically calibrated estimates of geolocation error are comparable to those reported in previous work, e.g. $-8.8 \mathrm{~m} \mathrm{yr}^{-1}$ in slant range and $-28.8 \mathrm{~m} \mathrm{yr}^{-1}$ in azimuth (Solgaard et al., 2021) and $-9.7 \mathrm{~m} \mathrm{yr}^{-1}$ in slant range and $-24.4 \mathrm{~m} \mathrm{yr}^{-1}$ in azimuth (Gisinger et al., 2021). The small difference between our estimates and those reported in literature can be due to the fact that we applied the subswathdependent geolocation error correction first. We note that the method of using the slowest $25 \%$ provides good estimates almost equivalent to those by using an external stable surface mask. In the processing, we only calibrate to the slowest $25 \%$ when there is insufficient overlap with the "stable surface" mask. Note the above velocity bias estimates are specifically referenced to 6-day Sentinel-1A/B image pairs with Sentinel-1A acquired prior to Sentinel-1B. 


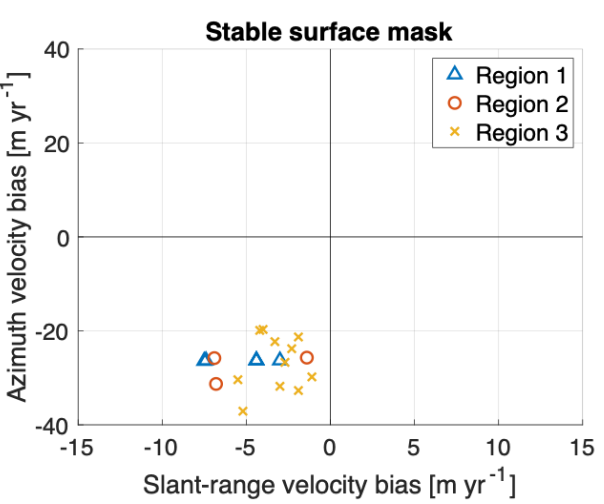

(a)

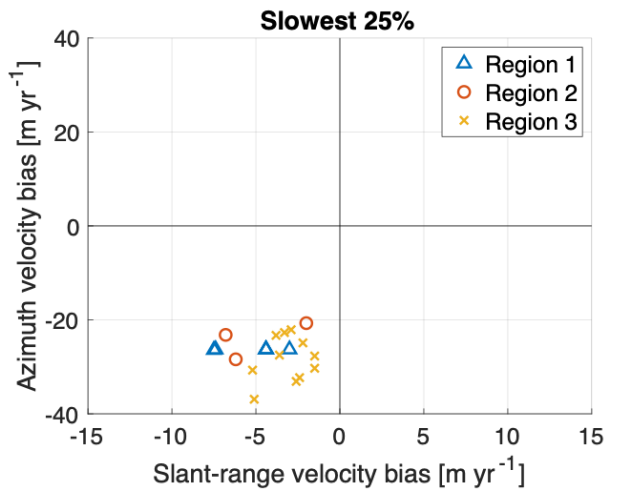

(b)

Figure 7: Full swath geolocation error-induced slant-range and azimuth velocity bias: (a) with stable surface mask, (b) considering the slowest $25 \%$ as stable surfaces. The 20 Sentinel-1A/B image pairs in Region 1, 2 and 3 are used. We use the pair convention of Sentinel-1A acquired prior to Sentinel-1B with 6-day time separation.

415 Scalar full swath-dependent bias corrections are applied and stored as stable_surface_mask and stable_surface_slow for each of the velocity variable in our ITS_LIVE Sentinel-1 product (Table 1). After the geolocation corrections are applied, the uncertainty in the velocities are calculated over the intersecting "stable surfaces" area when there is sufficient overlap, otherwise the calculations are made for the slowest $25 \%$. Uncertainties are taken as the standard error between calculated and the reference velocities.

\subsection{Ionosphere correction: ascending/descending combined velocity}

Remaining velocity errors are dominated by atmosphere delay effects, particularly ionospheric disturbance in the polar regions (Nagler et al., 2015; Solgaard et al., 2021). A common ionosphere effect on the offset tracking velocity products is azimuth pixel shifts due to the linear along-track variation of the ionosphere phase delay within the synthetic aperture. The shift is proportional to the linear rate of the ionosphere phase delay and inversely to the azimuth FM rate of the SAR platform (Meyer et al., 2006; Liang et al., 2019). This azimuth pixel shift usually results in long stripe-like artifacts, also called "azimuth streaks", in SAR-derived offset tracking maps. Such errors have been widely reported in the literature (Joughin et al., 1998; Gray et al., 2000; Joughin, 2002; Strozzi et al., 2008; Joughin et al., 2010; Mouginot et al., 2012; Rignot and Mouginot, 2012; Sánchez-Gámez and Navarro, 2017; Joughin et al., 2018; Liao et al., 2018). Traditional methods for removing these azimuth streaks are: stacking or weighted averaging of multiple velocity time-series estimates (Rignot and Mouginot, 2012; Joughin et al., 2018), and combining InSAR LOS phase measurements from ascending and descending passes (Joughin et al., 1998; Sánchez-Gámez and Navarro, 2017).

The impact of ionosphere phase delay on offset tracking velocity is more severe for azimuth velocities when using TOPS mode Sentinel-1 image pairs. This is because the azimuth resolution is roughly 5 times coarser than in range. Here we 
435 examine an approach to remove azimuth streaks in the ITS_LIVE Sentinel-1 image pair products. This approach exploits the LOS (slant range) measurements from the SAR acquisitions, which has the minimal impact from ionosphere disturbance.

With the LOS measurement from a single Sentinel-1 image pair (i.e. 1 observable) the $2 \mathrm{D}$ flow field is indeterminant. In the case of two image pairs with differing acquisition geometries (i.e. ascending and descending), we are provided with two independent LOS measurements from which the 2D flow field can be determined. This approach has been applied to InSAR LOS phase measurements (Joughin et al., 1998; Sánchez-Gámez and Navarro, 2017). Here we demonstrate how to apply this correction approach to the offset-tracking velocity layers in our ITS_LIVE Sentinel-1 image pair products.

As described in Section 2.1.3 and in Lei et al. (2021a), the Geogrid module provides a look-up table of $2 \times 2$ conversion 445 matrix between range/azimuth pixel displacements and $\mathrm{x}$-/y-direction velocity fields. Below we define the two elements from the first row of the conversion matrix as M11 and M12 (see Table 1; denoted as $M_{11}$ and $M_{12}$ ). The conversion matrix elements, M11 and M12, are stored in the final NetCDF file of the ITS_LIVE Sentinel-1 image pair product with a 32-bit floating point to 16-bit integer data compression to save space. The LOS (slant-range) measurement of pixel displacement (denoted by $D_{r}$ ) is thus connected to the desired x-/y-direction velocity fields ( $\mathbf{v x}$ and $\mathbf{v y}$; denoted by $v_{x}$ and $v_{y}$ ) via the 450 following relationship:

$D_{r}^{a}=M_{11}^{a} v_{x}+M_{12}^{a} v_{y}$,

for the ascending pair (with the superscript "a") and

$D_{r}^{d}=M_{11}^{d} v_{x}+M_{12}^{d} v_{y}$,

for the descending pair (with the superscript "d"). Note Eq. (3) and Eq. (4) formulate a system of two linear equations with

455 two unknowns. By inverting these two equations, we can solve for the velocity fields in map coordinates:

$\left(\begin{array}{l}v_{x} \\ v_{y}\end{array}\right)=\frac{1}{\left(M_{11}^{a} M_{12}^{d}-M_{12}^{a} M_{11}^{d}\right)}\left[\begin{array}{cc}M_{12}^{d} & -M_{12}^{a} \\ -M_{11}^{d} & M_{11}^{a}\end{array}\right]\left(\begin{array}{c}D_{r}^{a} \\ D_{r}^{d}\end{array}\right)$.

Thus, given two ITS_LIVE Sentinel-1 image pair products (i.e. NetCDF files), one is provided with all of the parameters needed to use Eq. (5) to calculate the map projected velocities solely from LOS measurements. Fig. 8 provides an example of this approach applied to ascending and descending Sentinel-1 image pairs both acquired on 20171226-20180101 in Region 3 (Table 2). 

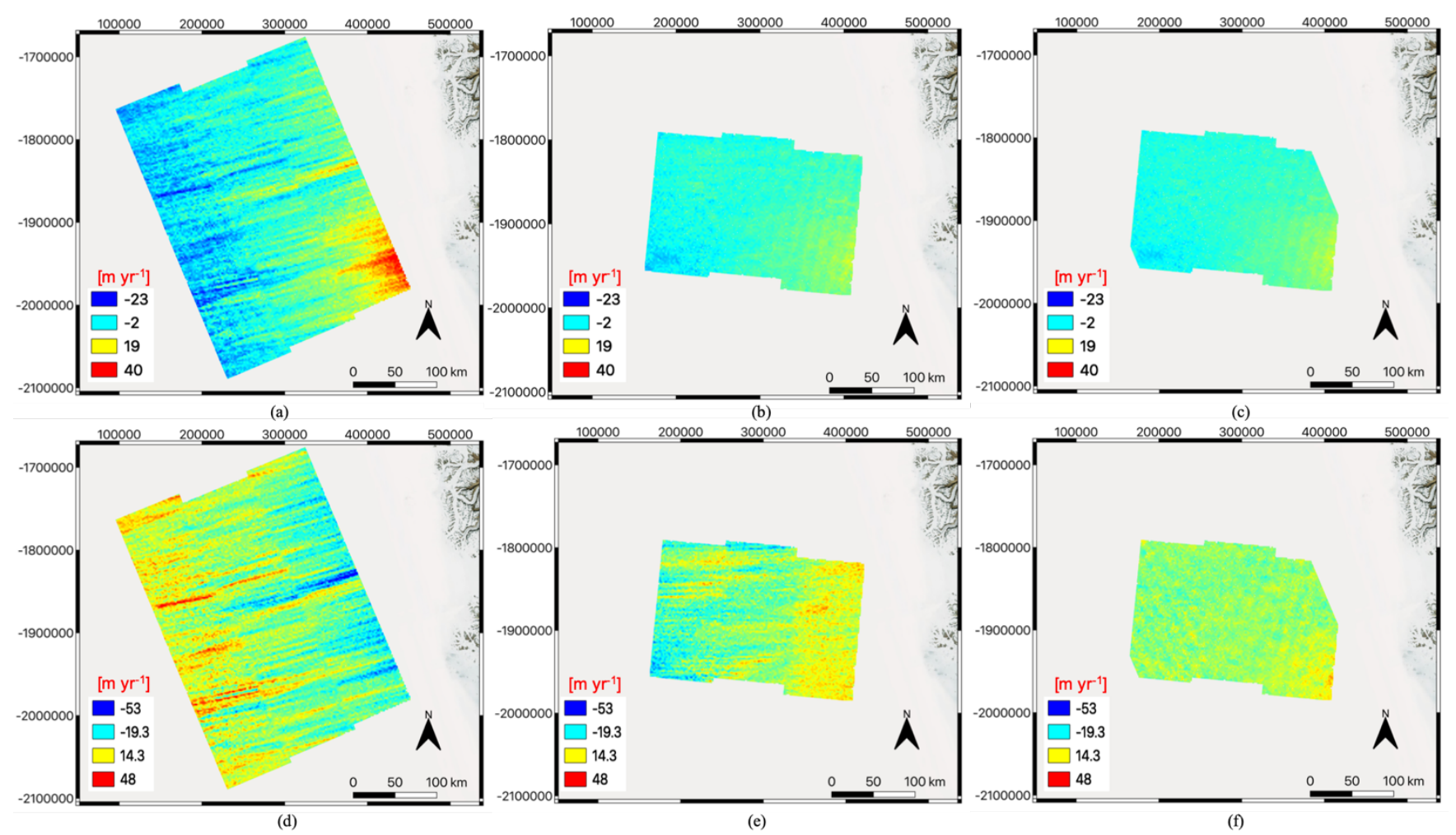

Figure 8: Ionosphere correction for ascending and descending acquisition geometry: (a) ascending $x$ velocity, (b) descending $x$ velocity, (c) ascending/descending combined $x$ velocity, (d) ascending $y$ velocity, (e) descending $y$ velocity, (f) ascending/descending combined $y$ velocity. The ascending/descending Sentinel-1 image pairs were both acquired on 20171226-20180101 in Region 3.

From Fig. 8a and Fig. 8d, it can be seen that that both $\mathrm{x}$ - and y-direction velocity from the ascending pair are severely contaminated by the ionosphere disturbance, because the inclination of the ascending orbit projects some amount of the azimuth streaking on both $\mathrm{x}$ - and y-directions. Fig. $8 \mathrm{~b}$ and Fig. $8 \mathrm{e}$ demonstrate the velocities for the descending pair. Since the descending orbit has a small inclination, the ionosphere disturbance is prominent in the y-direction velocity, which is more closely affected by the azimuth streaking. Fig. 8c and Fig. 8f show the final velocity fields obtained by combining the overlaps from both ascending and descending LOS measurements using Eq. (5), which significantly reduces the azimuth streaks as present in either of the two input image pairs. The uncertainty reduces from $8.6 \mathrm{~m} \mathrm{yr}^{-1}$ (ascending) or $3.7 \mathrm{~m} \mathrm{yr}^{-1}$ (descending) to $3.4 \mathrm{~m} \mathrm{yr}^{-1}$ (by 9-61\%) for the x-direction velocity and from $12.9 \mathrm{~m} \mathrm{yr}^{-1}$ (ascending) or 10.9 (descending) to $5.6 \mathrm{~m} \mathrm{yr}^{-1}$ (by 49-57\%) for the y-direction velocity. Therefore, significant reductions in velocity error can be achieved, when provided with two ITS_LIVE Sentinel-1 image pair products (i.e., NetCDF files only) acquired from ascending and descending geometry. 
https://doi.org/10.5194/essd-2021-393

Preprint. Discussion started: 14 December 2021

(c) Author(s) 2021. CC BY 4.0 License.

(c) (i)

\section{Summary and Conclusion}

In this paper we describe MEaSUREs ITS_LIVE Sentinel-1 Image-Pair Glacier and Ice Sheet Surface Velocities: Version 2 and the associated data processing algorithms. The dataset will be provided for all large glacierized regions. To demonstrate the data quality and algorithms we showcase 21 Sentinel-1 image-pairs (Lei et al., 2021b) over three different sites in Greenland: one covering the Jakobshavn Isbræ glacier to demonstrate algorithm performance in an area of fast flow and two other locations covering the interior of the ice sheet for calibration purposes.

We first summarized the ITS_LIVE Sentinel-1 image pair product along with the data processing chain. Both the inputs and outputs of the processing chain are introduced in detail. These image pair products are generated by using the offset tracking processing chain that consists of two Python modules: Geogrid and autoRIFT. In this work, the core offset tracking module, autoRIFT, has been enhanced with a few techniques for better accuracy, processing efficiency and to accommodate overlapping search chips for finer resolution. Benchmark comparisons between autoRIFT and ampcor show autoRIFT achieves multiple orders of magnitude improvement in efficiency, while at the same time providing a $\sim 33 \%$ reduction in uncertainty.

We then demonstrate approaches to reduce systematic error in Sentinel-1 image pair products. First, the slant-range/azimuth offset tracking results are calibrated for the subswath-dependent and full swath-dependent geolocation error for Sentinel1A/B pairs. By investigating 11 pairs, the average pixel offset bias between subswath 2 and 1 are -0.010 pixel in slant-range and 0.019 pixel in azimuth, while the bias between subswath 3 and 2 are -0.007 pixel in slant-range and 0.006 pixel in azimuth, which is referenced to an image pair with Sentinel-1A acquired prior to Sentinel-1B. These subswath offset bias estimates are then used as a static correction of the subswath-dependent geolocation error in each ITS_LIVE Sentinel-1 image pair product. Following this, the full swath-dependent geolocation error is corrected in a dynamic way for each image pair by using stable surfaces (ice-free terrain and slow-moving ice $<15 \mathrm{~m} \mathrm{yr}^{-1}$ ). Averaging 20 pairs, the calibrated velocity bias is $-4.07 \mathrm{~m} \mathrm{yr}^{-1}$ in slant range and $-26.81 \mathrm{~m} \mathrm{yr}^{-1}$ in azimuth, which is referenced to a 6-day Sentinel-1A/B pair with Sentinel-1A acquired prior to Sentinel-1B. A secondary method is tested with almost equivalent performance that uses the area of the slowest $25 \%$ of the reference velocity whenever the image pair does not intersect the stable surface. Even in well calibrated constellation missions, instrument-level differences that result in swath or subswath level offsets are inevitable as shown above. When Sentinel-1C and Sentinel-1D are launched, similar offset calibration exercises are needed before offsets generated from their imagery can be incorporated into ITS_LIVE like projects and/or processing campaigns.

To reduce the impact of ionosphere induced azimuth streaks, the product includes LOS parameters that support x/y horizontal velocity inversion from two slant-range measurements of both ascending and descending geometry. Using LOS measurements from two Sentinel-1 image pairs (one ascending and one descending) with 6-day separation, as well as the 
https://doi.org/10.5194/essd-2021-393

Preprint. Discussion started: 14 December 2021

(c) Author(s) 2021. CC BY 4.0 License.

(c) (i)

510 LOS parameter layers in the ITS_LIVE products, the uncertainty reduced from $8.55 \mathrm{~m} \mathrm{yr}^{-1}$ (ascending) or $3.68 \mathrm{~m} \mathrm{yr}^{-1}$ (descending) to $3.35 \mathrm{~m} \mathrm{yr}^{-1}$ (by 9-61\%) in the $\mathrm{x}$-direction and from $12.87 \mathrm{~m} \mathrm{yr}^{-1}$ (ascending) or 10.92 (descending) to $5.55 \mathrm{~m}$ $\mathrm{yr}^{-1}$ (by 49-57\%) in the y-direction. Using the ionosphere correction approach in this paper, there is still some residual slowvarying trend due to ionosphere disturbance in the LOS offset tracking velocity estimates, which could be removed by referencing to known ground control points with zero velocity through a quadratic baseline fit (Mouginot et al., 2012;

515 Joughin et al., 2018). As a future work, we plan to investigate the possibility of using split-spectrum InSAR phase (Liang et al., 2019) to remove the slow-varying ionosphere trend from the SAR LOS offset-tracking result over high-coherence areas, and then using the ionosphere correction approach (Section 3.2) in this paper to derive velocity products solely from corrected SAR LOS measurements, which could remarkably mitigate the artifacts from ionosphere-caused slow-varying trend (as well as azimuth streaks).

Other limitations and future work entail further improvements of the dynamic geolocation error calibration when the stable surface mask is unavailable within the spatial extent of the image pairs, ionosphere-induced azimuth streak removal by using an a-priori flow direction, as well as extensive validation of the products over various regions. By noting the limitations of the product, the described product specifics and processing methods will support the release of Version 2.0 ITS_LIVE ice

525 velocity products (https://its-live.jpl.nasa.gov; including image pair velocities, data cubes and mosaics) using Sentinel-1 radar sensor at global scales. The approaches presented here are also directly applicable to future radar satellite missions (e.g. NASA-ISRO's NISAR). It is our hope that by providing state-of-the-art, low latency, glacier velocity products to the public we will accelerate the understanding of glacier and ice sheet response to changes in ocean and atmosphere.

\section{Data availability}

530 The sample ITS_LIVE Sentinel-1 image pair products for the 21 Sentinel-1 image pairs used in this paper can be found at the following DOI: https://doi.org/10.5281/zenodo.5606118 (Lei et al., 2021b). The final release of Version 2.0 ITS_LIVE ice velocity products (including image pair maps, data cubes and mosaics) for Sentinel-1 as well as other optical sensors (Landsat-4/5/6/7/8 and Sentinel-2) can be found at the ITS_LIVE project website: https://its-live.jpl.nasa.gov.

\section{Software Tools}

535 The Version 2 ITS_LIVE Sentinel-1 image pair products (including the 21 samples in this paper) are processed with the following software tools. First, ISCE Version 2.4+ (https://github.com/isce-framework/isce2/releases; in particular the "topsApp" function) is used to preprocess the two Sentinel-1 images that form an image pair up to the step of "mergeBursts", which results in co-registered SLC images. Then, Geogrid/autoRIFT Version 1.4.0 (https://doi.org/10.5281/zenodo.5643820; in particular the "testGeogrid_ISCE" function followed by the "testautoRIFT_ISCE" function) is used to generate the final

540 NetCDF data product. Each of the above three steps (i.e., "topsApp", "testGeogrid_ISCE", "testautoRIFT_ISCE”) only involves a single command line. The readers are referred to the help page of ISCE (https://github.com/isce-framework/isce2), 
https://doi.org/10.5194/essd-2021-393

Preprint. Discussion started: 14 December 2021

(c) Author(s) 2021. CC BY 4.0 License.

(c) (1)

Geogrid (https://github.com/leiyangleon/Geogrid) and autoRIFT (https://github.com/nasa-jpl/autoRIFT) for more details.

Author contributions. AG and PA conceived the ITS LIVE project and the high-level designs of the Sentinel-1 ice velocity processing and data product. YL, AG and PA developed the processing software (autoRIFT/Geogrid), designed cal/val tests, and set up the format and layers of the final NetCDF product. YL prepared the manuscript with contributions from all co-authors.

Competing interests. Authors declare that they have no conflict of interest.

Acknowledgement. This effort was funded by the NASA MEaSUREs program in contribution to the Inter-mission Time Series of Land Ice Velocity and Elevation (ITS_LIVE) project (https://its-live.jpl.nasa.gov) and through Alex Gardner's participation in the NASA NISAR Science Team. 
https://doi.org/10.5194/essd-2021-393

Preprint. Discussion started: 14 December 2021

(c) Author(s) 2021. CC BY 4.0 License.

(c) (i)

555

Gardner, A. S., Fahnestock, M. A., and Scambos, T. A., 2019. ITS_LIVE Regional Glacier and Ice Sheet Surface Velocities., Data archived at National Snow and Ice Data Center, https://doi.org/10.5067/6II6VW8LLWJ7.

Gisinger, C., Schubert, A., Breit, H., Garthwaite, M., Balss, U., Willberg, M., Small, D., Eineder, M. and Miranda, N., 2020. In-depth verification of Sentinel-1 and TerraSAR-X geolocation accuracy using the Australian corner reflector

Gourmelen, N., Kim, S.W., Shepherd, A., Park, J.W., Sundal, A.V., Björnsson, H. and Pálsson, F., 2011. Ice velocity determined using conventional and multiple-aperture InSAR. Earth and Planetary Science Letters, 307(1-2), pp.156-160.

Gray, A.L., Mattar, K.E., Vachon, P.W., Bindschadler, R., Jezek, K.C., Forster, R. and Crawford, J.P., 1998, July. InSAR

Andersen, J.K., Kusk, A., Boncori, J.P.M., Hvidberg, C.S. and Grinsted, A., 2020. Improved ice velocity measurements with Sentinel-1 TOPS interferometry. Remote Sensing, 12(12), p.2014.

Bindschadler, R.A. and Scambos, T.A., 1991. Satellite-image-derived velocity field of an Antarctic ice stream. Science, 252(5003), pp.242-246.

Regression Approaches for Ice Velocity Derived by Landsat-8, Sentinel-1 and Sentinel-2. Remote Sensing, 12(12), p. 1935.

Geoscience and Remote Sensing, 44(9), pp.2352-2360.

Fahnestock, M., Bindschadler, R., Kwok, R. and Jezek, K., 1993. Greenland ice sheet surface properties and ice dynamics from ERS-1 SAR imagery. Science, 262(5139), pp.1530-1534.

Fahnestock, M., Scambos, T., Moon, T., Gardner, A., Haran, T. and Klinger, M., 2016. Rapid large-area mapping of ice flow

Frolich, R.M. and Doake, C.S.M., 1998. Synthetic aperture radar interferometry over Rutford Ice Stream and Carlson Inlet, Antarctica. Journal of Glaciology, 44(146), pp.77-92.

Gardner, A.S., Moholdt, G., Scambos, T., Fahnstock, M., Ligtenberg, S., Broeke, M.V.D. and Nilsson, J., 2018. Increased West Antarctic and unchanged East Antarctic ice discharge over the last 7 years. The Cryosphere, 12(2), pp.521547. array. IEEE Transactions on Geoscience and Remote Sensing, 59(2), pp.1154-1181.

results from the RADARSAT Antarctic Mapping Mission data: estimation of glacier motion using a simple registration procedure. In IGARSS'98. Sensing and Managing the Environment. 1998 IEEE International Geoscience and Remote Sensing. Symposium Proceedings.(Cat. No. 98CH36174) (Vol. 3, pp. 1638-1640). IEEE. 
https://doi.org/10.5194/essd-2021-393

Preprint. Discussion started: 14 December 2021

(c) Author(s) 2021. CC BY 4.0 License.

(c) (i)

Gray, A.L., Mattar, K.E. and Sofko, G., 2000. Influence of ionospheric electron density fluctuations on satellite radar interferometry. Geophysical Research Letters, 27(10), pp.1451-1454.

Howat, I.M., Negrete, A. and Smith, B.E., 2014. The Greenland Ice Mapping Project (GIMP) land classification and surface elevation data sets. The Cryosphere, 8(4), pp.1509-1518.

Howat, I.; Negrete, A.; Smith, B., 2015. MEaSUREs Greenland Ice Mapping Project (GIMP) Digital Elevation Model, Version 1; NASA National Snow and Ice Data Center Distributed Active Archive Center: Boulder, CO, USA. Available online: https://doi.org/10.5067/NV34YUIXLP9W (accessed on 2 July 2020).

IPCC AR6: https://www.ipcc.ch/assessment-report/ar6/ (accessed on 22 October 2021)

Jiao, Y., Morton, Y.T., Taylor, S. and Pelgrum, W., 2013. Characterization of high-latitude ionospheric scintillation of GPS signals. Radio Science, 48(6), pp.698-708.

Joughin, I.R., Winebrenner, D.P. and Fahnestock, M.A., 1995. Observations of ice-sheet motion in Greenland using satellite radar interferometry. Geophysical Research Letters, 22(5), pp.571-574.

600 Joughin, I.R., Kwok, R. and Fahnestock, M.A., 1998. Interferometric estimation of three-dimensional ice-flow using ascending and descending passes. IEEE Transactions on Geoscience and Remote Sensing, 36(1), pp.25-37.

Joughin, I., Gray, L., Bindschadler, R., Price, S., Morse, D., Hulbe, C., Mattar, K. and Werner, C., 1999. Tributaries of West Antarctic ice streams revealed by RADARSAT interferometry. Science, 286(5438), pp.283-286.

Joughin, I., 2002. Ice-sheet velocity mapping: a combined interferometric and speckle-tracking approach. Annals of Glaciology, 34, pp.195-201.

Joughin, I., Smith, B.E., Howat, I.M., Scambos, T. and Moon, T., 2010. Greenland flow variability from ice-sheet-wide velocity mapping. Journal of Glaciology, 56(197), pp.415-430.

Joughin, I.; Smith, B.; Howat, I.; Scambos, T., 2016. MEaSUREs Multi-year Greenland Ice Sheet Velocity Mosaic, Version 1; NASA National Snow and Ice Data Center Distributed Active Archive Center: Boulder, CO, USA. Available online: https://doi.org/10.5067/QUA5Q9SVMSJG (accessed on 2 July 2020).

Joughin, I.A.N., Smith, B.E. and Howat, I.M., 2018. A complete map of Greenland ice velocity derived from satellite data collected over 20 years. Journal of Glaciology, 64(243), pp.1-11.

Joughin, I., 2020a. MEaSUREs Greenland Annual Ice Sheet Velocity Mosaics from SAR and Landsat, Version 2., Boulder, Colorado USA. NASA National Snow and Ice Data Center Distributed Active Archive Center., https://doi.org/10.5067/TZZDYD94IMJB.

Joughin, I., 2020b. MEaSUREs Greenland Monthly Ice Sheet Velocity Mosaics from SAR and Landsat, Version 2., Boulder, Colorado USA. NASA National Snow and Ice Data Center Distributed Active Archive Center., https://doi.org/0.5067/11MJZGPBK3ZF.

Kääb, A., Winsvold, S.H., Altena, B., Nuth, C., Nagler, T. and Wuite, J., 2016. Glacier remote sensing using Sentinel-2. part I: Radiometric and geometric performance, and application to ice velocity. Remote Sensing, 8(7), p.598. 
https://doi.org/10.5194/essd-2021-393

Preprint. Discussion started: 14 December 2021

(c) Author(s) 2021. CC BY 4.0 License.

(c) (i)

Kusk, A., Boncori, J.P.M. and Dall, J., 2018, June. An automated system for ice velocity measurement from SAR. In EUSAR 2018; 12th European Conference on Synthetic Aperture Radar (pp. 1-4). VDE.

Lei, Y., Gardner, A. and Agram, P., 2021a. Autonomous Repeat Image Feature Tracking (autoRIFT) and Its Application for Tracking Ice Displacement. Remote Sens. 2021, 13, 749.

Lei, Y., Gardner, A. and Agram, P., 2021b. MEaSUREs ITS_LIVE Sentinel-1 Image-Pair Glacier and Ice Sheet Surface Velocities: Version 2 (Greenland sample products). https://doi.org/10.5281/zenodo.5606118.

Liang, C., Agram, P., Simons, M. and Fielding, E.J., 2019. Ionospheric correction of InSAR time series analysis of C-band Sentinel-1 TOPS data. IEEE Transactions on Geoscience and Remote Sensing, 57(9), pp.6755-6773.

Liao, H., Meyer, F.J., Scheuchl, B., Mouginot, J., Joughin, I. and Rignot, E., 2018. Ionospheric correction of InSAR data for accurate ice velocity measurement at polar regions. Remote Sensing of Environment, 209, pp.166-180.

Meyer, F., Bamler, R., Jakowski, N. and Fritz, T., 2006. The potential of low-frequency SAR systems for mapping ionospheric TEC distributions. IEEE Geoscience and Remote Sensing Letters, 3(4), pp.560-564.

Michel, R. and Rignot, E., 1999. Flow of Glaciar Moreno, Argentina, from repeat-pass Shuttle Imaging Radar images: comparison of the phase correlation method with radar interferometry. Journal of Glaciology, 45(149), pp.93-100.

Miles, K.E., Willis, I.C., Benedek, C.L., Williamson, A.G. and Tedesco, M., 2017. Toward monitoring surface and subsurface lakes on the Greenland ice sheet using Sentinel-1 SAR and Landsat-8 OLI imagery. Frontiers in Earth Science, 5, p.58.

Miranda, N., Meadows, P., Piantanida, R., Recchia, A., Small, D., Schubert, A., Vincent, P., Geudtner, D., Navas-Traver, I. and Vega, F.C., 2017, July. The Sentinel-1 constellation mission performance. In 2017 IEEE International Geoscience and Remote Sensing Symposium (IGARSS) (pp. 5541-5544). IEEE.

Mouginot, J., Scheuchl, B. and Rignot, E., 2012. Mapping of ice motion in Antarctica using synthetic-aperture radar data. Remote Sensing, 4(9), pp.2753-2767.

Mouginot, J., Rignot, E., Scheuchl, B. and Millan, R., 2017. Comprehensive annual ice sheet velocity mapping using Landsat-8, Sentinel-1, and RADARSAT-2 data. Remote Sensing, 9(4), p.364.

Mouginot, J., Rignot, E. and Scheuchl, B., 2019a. Continent-wide, interferometric SAR phase, mapping of Antarctic ice velocity. Geophysical Research Letters, 46(16), pp.9710-9718.

Mouginot, J., Rignot, E., Scheuchl, B., Wood, M., and Millan, R., 2019b. Annual Ice Velocity of the Greenland Ice Sheet (2010-2017), Dryad, Dataset., https://doi.org/10.7280/D11H3X.

Nagler, T., Rott, H., Hetzenecker, M., Scharrer, K., Magnússon, E., Floricioiu, D. and Notarnicola, C., 2012, July. Retrieval of 3D-glacier movement by high resolution X-band SAR data. In 2012 IEEE International Geoscience and Remote Sensing Symposium (pp. 3233-3236). IEEE.

Nagler, T., Rott, H., Hetzenecker, M., Wuite, J. and Potin, P., 2015. The Sentinel-1 mission: New opportunities for ice sheet observations. Remote Sensing, 7(7), pp.9371-9389. 
Nagy, T. and Andreassen, L.M., 2019. Glacier surface velocity mapping with Sentinel-2 imagery in Norway. Rapport, engelsknr 37.

Prats-Iraola, P., Nannini, M., Scheiber, R., De Zan, F., Wollstadt, S., Minati, F., Vecchioli, F., Costantini, M., Borgstrom, S., De Martino, P. and Siniscalchi, V., 2015, July. Sentinel-1 assessment of the interferometric wide-swath mode. In 2015 IEEE international geoscience and remote sensing symposium (IGARSS) (pp. 5247-5251). IEEE.

Rignot, E., Jezek, K.C. and Sohn, H.G., 1995. Ice flow dynamics of the Greenland ice sheet from SAR interferometry. Geophysical Research Letters, 22(5), pp.575-578.

Rignot, E. and Mouginot, J., 2012. Ice flow in Greenland for the international polar year 2008-2009. Geophysical Research Letters, 39(11).

Riveros, N., Euillades, L., Euillades, P., Moreiras, S. and Balbarani, S., 2013. Offset tracking procedure applied to high resolution SAR data on Viedma Glacier, Patagonian Andes, Argentina. Advances in Geosciences, 35, pp.7-13.

Sánchez-Gámez, P. and Navarro, F.J., 2017. Glacier surface velocity retrieval using D-InSAR and offset tracking techniques applied to ascending and descending passes of Sentinel-1 data for southern Ellesmere ice caps, Canadian Arctic. Remote Sensing, 9(5), p.442.

Schubert, A., Miranda, N., Geudtner, D. and Small, D., 2017. Sentinel-1A/B combined product geolocation accuracy. Remote sensing, 9(6), p.607.

670 Solgaard, A., Kusk, A., Merryman Boncori, J.P., Dall, J., Mankoff, K.D., Ahlstrøm, A.P., Andersen, S.B., Citterio, M., Karlsson, N.B., Kjeldsen, K.K. and Korsgaard, N.J., 2021. Greenland ice velocity maps from the PROMICE project. Earth System Science Data, 13(7), pp.3491-3512.

Stein, A.N., Huertas, A. and Matthies, L., 2006, May. Attenuating stereo pixel-locking via affine window adaptation. In Proceedings 2006 IEEE International Conference on Robotics and Automation, 2006. ICRA 2006. (pp. 914-921). IEEE.

Strozzi, T., Luckman, A., Murray, T., Wegmuller, U. and Werner, C.L., 2002. Glacier motion estimation using SAR offsettracking procedures. IEEE Transactions on Geoscience and Remote Sensing, 40(11), pp.2384-2391.

Strozzi, T., Kouraev, A., Wiesmann, A., Wegmüller, U., Sharov, A. and Werner, C., 2008. Estimation of Arctic glacier motion with satellite L-band SAR data. Remote Sensing of Environment, 112(3), pp.636-645.

680 Yu, J., Liu, H., Jezek, K.C., Warner, R.C. and Wen, J., 2010. Analysis of velocity field, mass balance, and basal melt of the Lambert Glacier-Amery Ice Shelf system by incorporating Radarsat SAR interferometry and ICESat laser altimetry measurements. Journal of Geophysical Research: Solid Earth, 115(B11). 